\title{
Cannabinoids promote embryonic and adult hippocampus neurogenesis and produce anxiolytic- and antidepressant-like effects
}

\author{
Wen Jiang, ${ }^{1,2}$ Yun Zhang, ${ }^{1}$ Lan Xiao, ${ }^{1}$ Jamie Van Cleemput, ${ }^{1}$ \\ Shao-Ping Ji, ${ }^{1}$ Guang Bai, ${ }^{3}$ and Xia Zhang ${ }^{1}$ \\ ${ }^{1}$ Neuropsychiatry Research Unit, Department of Psychiatry, University of Saskatchewan, Saskatoon, Saskatchewan, Canada. \\ 2Department of Neurology, Xijing Hospital, Fourth Military Medical University, Xi'an, People's Republic of China. \\ ${ }^{3}$ Department of Biomedical Sciences, Dental School, Program in Neuroscience, University of Maryland, Baltimore, Maryland, USA.
}

\begin{abstract}
The hippocampal dentate gyrus in the adult mammalian brain contains neural stem/progenitor cells (NS/PCs) capable of generating new neurons, i.e., neurogenesis. Most drugs of abuse examined to date decrease adult hippocampal neurogenesis, but the effects of cannabis (marijuana or cannabinoids) on hippocampal neurogenesis remain unknown. This study aimed at investigating the potential regulatory capacity of the potent synthetic cannabinoid HU210 on hippocampal neurogenesis and its possible correlation with behavioral change. We show that both embryonic and adult rat hippocampal NS/PCs are immunoreactive for CB1 cannabinoid receptors, indicating that cannabinoids could act on $\mathrm{CB} 1$ receptors to regulate neurogenesis. This hypothesis is supported by further findings that HU210 promotes proliferation, but not differentiation, of cultured embryonic hippocampal NS/PCs likely via a sequential activation of CB1 receptors, $G_{i / o}$ proteins, and ERK signaling. Chronic, but not acute, HU210 treatment promoted neurogenesis in the hippocampal dentate gyrus of adult rats and exerted anxiolytic- and antidepressant-like effects. $X$-irradiation of the hippocampus blocked both the neurogenic and behavioral effects of chronic HU210 treatment, suggesting that chronic HU210 treatment produces anxiolytic- and antidepressant-like effects likely via promotion of hippocampal neurogenesis.
\end{abstract}

\section{Introduction}

Cannabis (marijuana, hashish, or cannabinoids) has been used for medical and recreational purposes for many centuries and is likely the only medicine or illicit drug that has constantly evoked tremendous interest or controversy within both the public domain and medical research. Cannabinoids appear to be able to modulate pain, nausea, vomiting, epilepsy, ischemic stroke, cerebral trauma, multiple sclerosis, tumors, and other disorders in humans and/or animals (1-7). However, marijuana has been the most commonly used illicit drug in developed countries, producing acute memory impairment and dependence/withdrawal symptoms in chronic users and animal models $(6,8-10)$. Cannabis acts on 2 types of cannabinoid receptors, the CB1 and CB2 receptors, which are distributed mainly in the brain and immune system, respectively. In the brain, CB1 receptors are also targeted by endogenous cannabinoids (i.e., endocannabinoids) such as anandamide (AEA), 2-arachidonylglycerol, and arachidonylethanolamide $(1,6,10,11)$.

The recent discovery that the hippocampus is able to generate new neurons (i.e., neurogenesis) throughout the lifespan of mammals, including humans, has changed the way we think about the mechanisms of psychiatric disorders (12) and drug addiction (13). The subgranular zone of the dentate gyrus (SGZ) in the adult brain contains neural stem/progenitor cells (NS/PCs) capable of

Nonstandard abbreviations used: AEA, anandamide; FST, forced swimming test; NeuN, neuronal nuclear antigen; NSF, novelty-suppressed feeding; NS/PC, neural stem/progenitor cell; pERK1/2, phospho-ERK1/2; SGZ, subgranular zone of the dentate gyrus; TuJ1, $\beta$-tubulin III.

Conflict of interest: The authors have declared that no conflict of interest exists.

Citation for this article: J. Clin. Invest. 115:3104-3116 (2005).

doi:10.1172/JCI25509. producing thousands of new granule cells per day (14). We, and others, have shown that these newborn hippocampal neurons are functionally integrated into the existing neuroanatomical circuitry $(15,16)$ and are positively correlated with hippocampus-dependent learning and memory processes (17) and the developmental mechanisms of stress and mood disorders (12). Recent studies have further shown that chronic fluoxetine treatment produced antidepressant and anxiolytic effects $(18,19)$ and the anxiolytic effects are likely achieved by promoting hippocampal neurogenesis (18).

Chronic administration of the major drugs of abuse including opiates, alcohol, nicotine, and cocaine has been reported to suppress hippocampal neurogenesis in adult rats (20-23), suggesting a potential role of hippocampal neurogenesis in the initiation, maintenance, and treatment of drug addiction (13). The recent finding of prominently decreased hippocampal neurogenesis in CB1-knockout mice (24) suggests that CB1 receptor activation by endogenous, plant-derived, or synthetic cannabinoids may promote hippocampal neurogenesis. However, endogenous cannabinoids have been reported to inhibit adult hippocampal neurogenesis (25). Nevertheless, it is possible that exo- and endocannabinoids could differentially regulate hippocampal neurogenesis, as exo- and endocannabinoids act as full or partial agonists on CB1 receptors, respectively (11).

The goal of the present study was to test the hypothesis that the potent synthetic cannabinoid HU210 is able to promote hippocampal neurogenesis, leading to the anxiolytic and antidepressant effects of cannabinoids. We demonstrate here that both HU210 and the endocannabinoid AEA promote proliferation of embryonic hippocampal NS/PCs without significant effects on their differentiation, resulting in more newborn neurons. The effects of HU210 on adult hippocampal neurogenesis were quan- 
A

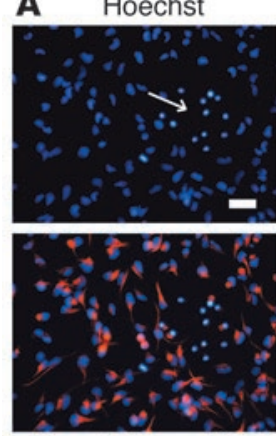

Hoechst + nestin

B $\mathrm{kDa}$

$72-$

55
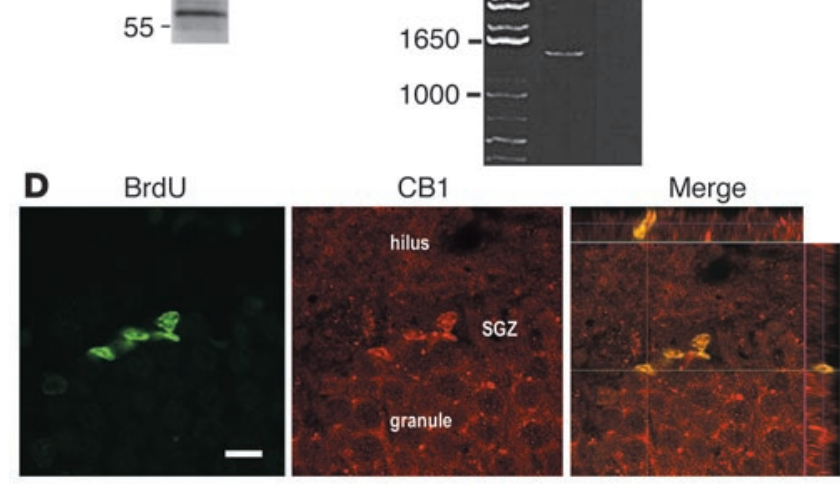
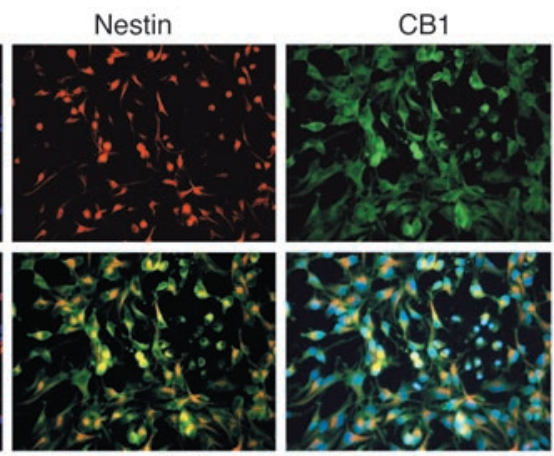

Nestin + CB1

C

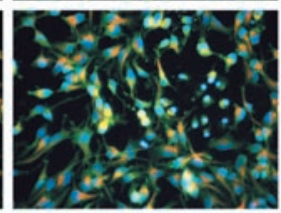

Hoechst + nestin + CB1

23

tified in freely moving rats and were correlated with behavioral testing. We show that 1 month after chronic HU210 treatment, rats display increased newborn neurons in the hippocampal dentate gyrus and significantly reduced measures of anxiety- and depression-like behavior. Thus, cannabinoids appear to be the only illicit drug whose capacity to produce increased hippocampal newborn neurons is positively correlated with its anxiolytic- and antidepressant-like effects.

\section{Results}

Expression of CB1 receptors in embryonic and adult hippocampal NS/PCs. In the mammalian brain, the $\mathrm{CB} 1$ receptor is one of the most abundant $G$ protein-coupled receptors, accounting for most, if not all, of the centrally mediated effects of cannabinoids (5). We reasoned that if cannabinoids were able to regulate neurogenesis, the NS/PCs capable of producing new neural cells would contain CB1 receptors. We therefore employed CB1 antibody immunocytochemistry, Western blotting, and PCR to examine CB1 protein and gene expression in cultured NS/PCs isolated from the hippocampus of E17 rat embryos. About $95 \%$ of the total neurosphere cells labeled with Hoeschst stain were also labeled with both CB1 and nestin (a marker for NS/PCs) antibodies (Figure 1A). Some Hoechst-labeled cells in the neurospheres exhibited the shape of glial cells, with small round nuclei, and were CB1 immunoreactive but without nestin staining (Figure 1A). The staining of CB1 antibody appears specific for 2 reasons. First, Western blots with the same antibody and cultured NS/PC revealed a strong protein band with the molecular weight of $60 \mathrm{kDa}$ (Figure 1B), which corresponds to the CB1 receptor (26). Second, we could not detect the positive immunostaining or $60-\mathrm{kDa}$ protein band using the $\mathrm{CB} 1$ antibody preabsorbed with the anti-

\section{Figure 1}

Expression of CB1 receptors in NS/PCs. (A) Coimmunofluorescent staining of $\mathrm{CB} 1$ and nestin in cultured hippocampal NS/PCs derived from E17 embryos. Hoechst staining was conducted to reveal the total cultured cells. The arrow indicates the glial-like cells, located in the center of a neurosphere, with $\mathrm{CB} 1$ staining and without nestin staining. Scale bar, $20 \mu \mathrm{m}$. (B) Western blot using cultured NS/PC reveals a $60-\mathrm{kDa}$ protein band corresponding to CB1 receptor. (C) PCR indicates CB1 gene expression in NS/PCs (lane 2 ) using primers yielding a predicted product of $1,440 \mathrm{bp}$ (i.e., the full encoding region of $\mathrm{CB} 1$ receptor) from embryonic NS/PCs. Lane 1: molecular weight standards; lane 2: CB1 receptor; lane 3: PCR reaction without sample added. (D) Confocal microscopic assessments of costaining of BrdU and CB1 receptors in the SGZ located between the hilus and the granule cell layer (granule) of the dentate gyrus in an adult rat. Scale bar, $10 \mu \mathrm{m}$.

gen. Using PCR, we further identified a band of the predicted size $(1,440 \mathrm{bp})$ corresponding to the full encoding region of CB1 (Figure 1C), suggesting the presence of CB1 transcripts in NS/PCs. Similar results, i.e., CB1 protein and gene expression, were seen in both second and sixth passages of NS/PCs. We then examined adult naive rats sacrificed 2 hours after receiving a single dose of BrdU to label dividing cells. We found that about $90 \%$ of BrdU-stained cells in the SGZ were also doubly labeled with CB1 (Figure 1D; $n=3$ ). These results suggest that both embryonic and adult hippocampal NS/PCs express CB1 receptors.

Increased proliferation of embryonic NS/PCs by HU210 and AEA. To examine the effects of HU210 on NS/PC proliferation, cultured embryonic NS/PCs were incubated with different concentrations of HU210. With the WST-8 assay, changes in NS/PC proliferation between HU210- and vehicle-treated culture were significant at some concentrations of HU210, as evidenced by significant group effects with 1 -way $\operatorname{ANOVA}\left(F_{5,18}=513.129, P<0.01\right)$. Specifically, when $10 \mathrm{nM}$ to $1 \mu \mathrm{M}$ of HU210 were added to the culture medium containing the mitogenic growth factors bFGF and EGF, the WST-8 assay showed a significant increase in NS/PC proliferation (Tukey post-hoc tests, $P<0.05) ; 1$ nM of HU210 exerted no significant effects $(P=0.072) ; 10 \mu \mathrm{M}$ produced profound toxic effects on cultured NS/PCs (Figure 2A). Because HU210 can activate both CB1 and CB2 receptors, we next used the selective CB1 receptor antagonist AM281 to identify the possible involvement of CB1 in the action of HU210 on NS/PC proliferation. Although $1 \mathrm{nM}$ to $1 \mu \mathrm{M}$ of AM281 alone produced no significant effects on NS/PC proliferation, $10 \mathrm{nM}$ to $1 \mu \mathrm{M}$ of AM281 blocked the promoting effects of $10 \mathrm{nM}$ to $1 \mu \mathrm{M}$ of HU210 on NS/PC proliferation (1-way ANOVA for repeated measures, $F_{2,25.713}=16.792, P<0.01$; pairwise comparisons, HU210-treated cells with or without AM281: $P<0.01$ ) (Figure 2A), suggesting that HU210 specifically acts on CB1 receptors to promote NS/PC proliferation. While $10 \mu \mathrm{M}$ of AM281 alone significantly inhibited NS/PC proliferation $(P<0.01)$, this concentration of AM281 did not exert significant effects in preventing the lethal effects of $10 \mu \mathrm{M}$ of HU210 on NS/PCs (Figure 2A), indicating that the lethal effects of $10 \mu \mathrm{M}$ of HU210 on NS/PC cells were caused nonspecifically or by another receptor.

To confirm the effects of $10 \mathrm{nM}$ to $1 \mu \mathrm{M}$ of HU210 on promoting NS/PC proliferation as previously assessed by the WST-8 assay, the BrdU incorporation assay was used. It measures cell proliferation by detecting dividing cells. Similar to the results of the WST-8 assay, 1-way ANOVA showed significant group effects $\left(F_{5,18}=176.004 ; P<0.01\right)$; Tukey post-hoc tests revealed that $10 \mathrm{nM}$ 
A

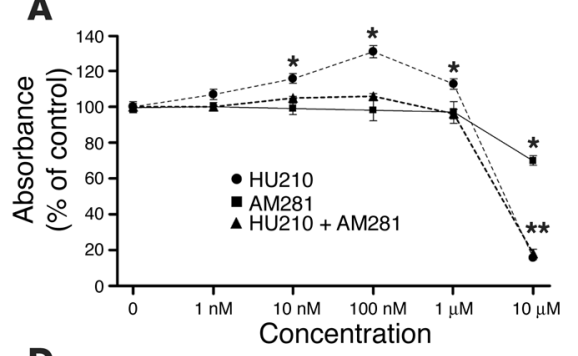

D

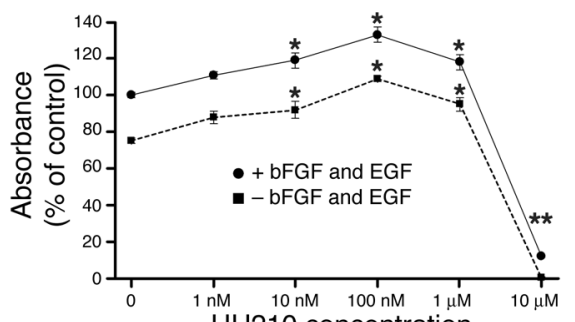

G

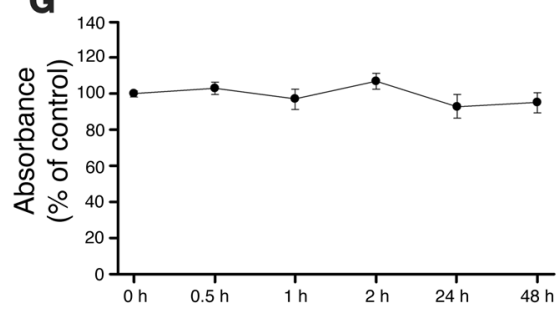

B

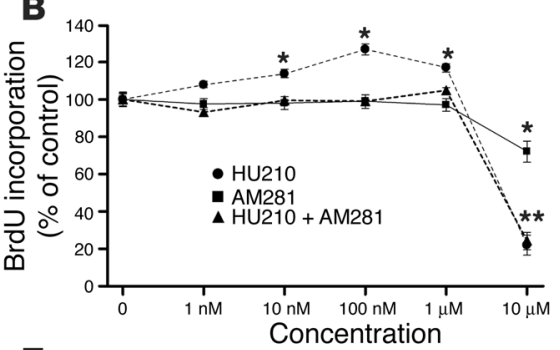

E

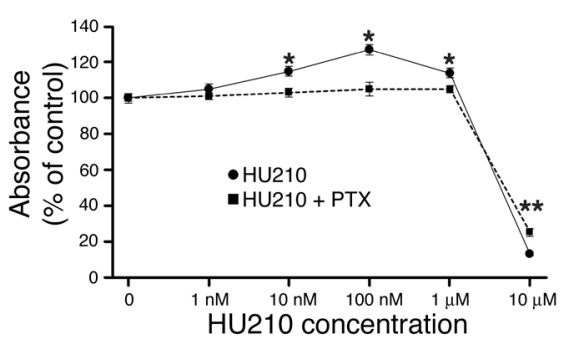

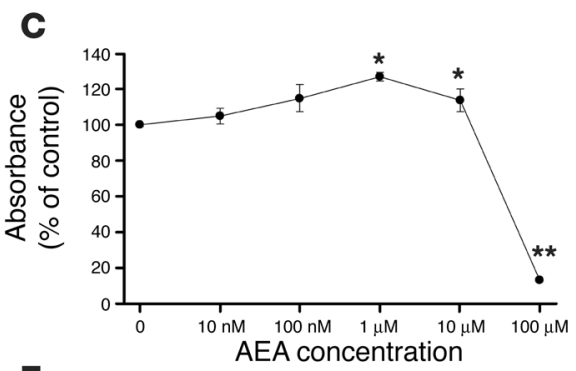

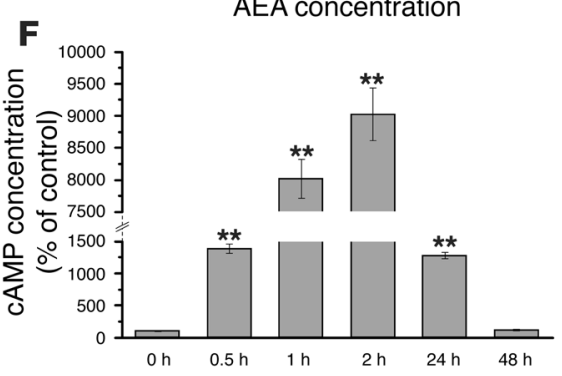

Figure 2

Effects of the cannabinoid HU210 on proliferation of cultured hippocampal NS/PCs. (A) In the WST-8 assay, incubation of NS/PCs with $10 \mathrm{nM}$ to $1 \mu \mathrm{M}$ of HU210 for 48 hours significantly promoted NS/PC proliferation, which was blocked by the CB1 receptor antagonist AM281. AM281 alone significantly decreased NS/PC proliferation only with $10 \mu \mathrm{M}$, but this concentration of AM281 was not able to block the lethal effects of $10 \mu \mathrm{M}$ of HU210 on NS/PCs. (B) BrdU incorporation assay confirmed the results obtained with the WST-8 assay shown in A. (C) Incubation of NS/PCs with $1 \mu \mathrm{M}$ to $10 \mu \mathrm{M}$ of AEA for 48 hours significantly promoted NS/PC proliferation in the WST-8 assay. (D) Application of $10 \mathrm{nM}$ to $1 \mu \mathrm{M}$ of HU210 significantly promoted NS/PC proliferation in both the presence and absence of the growth factors bFGF and EGF in the culture medium. (E) Pertussis (PTX; $100 \mathrm{ng} / \mathrm{ml}$ ), a selective blocker for $\mathrm{G}_{\mathrm{i} / \mathrm{o}}$ protein activation, prevented the effects of $10 \mathrm{nM}$ to $1 \mu \mathrm{M}$ of HU210 on promoting NS/PC proliferation. (F) Incubation of NS/PCs with $1 \mathrm{mg} / \mathrm{ml}$ of cholera toxin, a selective $\mathrm{G}_{\mathrm{s}}$ activator, stimulated a profound increase in cAMP accumulation in NS/PCs $0.5,1,2$, and 24 hours after the addition of cholera toxin. (G) Incubation of NS/PCs with $1 \mathrm{mg} / \mathrm{ml}$ of cholera toxin for $0.5,1,2,24$, or 48 hours did not induce significant change in NS/PC proliferation. Error bars represent SEM. ${ }^{*} P<0.05$ and ${ }^{*} P<0.01$ by Tukey post-hoc tests after 1-way ANOVA.

to $1 \mathrm{\mu M}$ of HU210 significantly increased NS/PC proliferation $(P<0.05)$, which was blocked by $10 \mathrm{nM}$ to $1 \mu \mathrm{M}$ of the selective CB1 receptor antagonist AM281 (1-way ANOVA for repeated measures, $F_{2,36}=19.081, P<0.01$; pairwise comparisons, HU210-treated cells with or without AM281: $P<0.01$ ) (Figure $2 \mathrm{~B}$ ).

To determine the effects of the endogenous cannabinoid AEA on NS/PC proliferation, cultured NS/PCs were incubated with different concentrations of AEA. The WST-8 assay showed significant group effects with 1 -way ANOVA $\left(F_{5,18}=61.585, P<0.01\right)$. Tukey post-hoc tests further showed that $1 \mu \mathrm{M}$ to $10 \mu \mathrm{M}$ of AEA significantly increased NS/PC proliferation $(P<0.05)$ in the presence of bFGF and EGF; $100 \mu \mathrm{M}$ produced toxic effects (Figure 2C).

To explore the possibility of whether HU210 itself is able to produce mitogenic effects, we further examined NS/PC proliferation by adding different concentrations of HU210 to the culture medium with or without the mitogenic growth factors bFGF and EGF. When bFGF and EGF were absent from the culture medium, a significant overall change in NS/PC proliferation was observed following HU210 application $\left(F_{5,30}=219.076, P<0.01\right)($ Figure 2D).
Specifically, $10 \mathrm{nM}$ to $1 \mu \mathrm{M}$ of HU210 without growth factors produced significant mitogenic effects on NS/PCs (Tukey post-hoc tests, $P<0.05$ ), whereas $10 \mu \mathrm{M}$ of HU210 killed the cells. Similar results were observed in the control culture when different concentrations of HU210 were added to the culture medium containing the mitogenic growth factors $\left(F_{5,30}=194.429, P<0.01\right.$; Tukey posthoc tests, $P<0.05$ ) (Figure 2D). Nevertheless, the basal proliferation levels with $\mathrm{bFGF}$ and EGF were significantly higher than those without bFGF and EGF (1-way ANOVA for repeated measures, $F_{1,30}=214.703, P<0.01$; pairwise comparisons: $P<0.01$ ) (Figure 2D). Intracellular signaling involved in HU210-induced NS/PC proliferation. To investigate the mechanisms underlying the action of HU210 on NS/PC proliferation, we examined the intracellular signaling pathways. CB1 receptor stimulation activates $\mathrm{G}_{\mathrm{i} / \mathrm{o}}$ or $\mathrm{G}_{\mathrm{s}}$ proteins $(27,28)$. To examine whether $\mathrm{G}_{\mathrm{i} / \mathrm{o}}$ protein mediates the effects of $\mathrm{HU} 210$, we added pertussis toxin, a selective blocker for $\mathrm{G}_{\mathrm{i} / \mathrm{o}}$ protein activation, to the culture medium 4 hours prior to HU210 treatment. Again, $10 \mathrm{nM}$ to $1 \mu \mathrm{M}$ of HU210 significantly increased NS/PC proliferation (1-way ANOVA, $F_{5,18}=880.629, P<0.01$; post- 

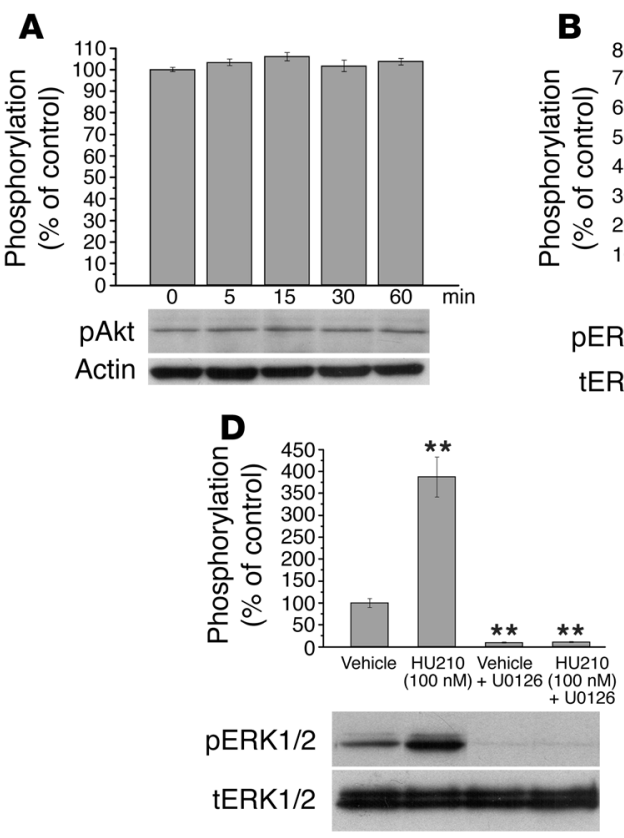

B
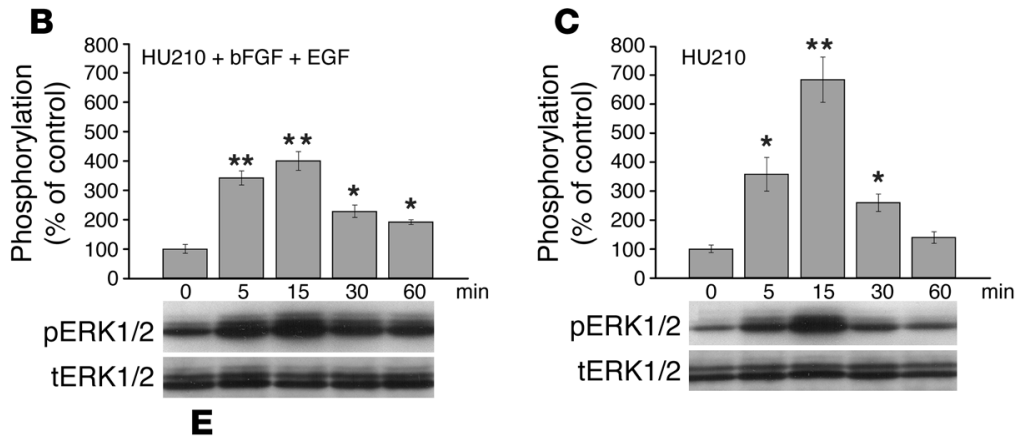

Figure 3

Effects of the cannabinoid HU210 on PI3K/Akt and ERK signaling in cultured hippocampal NS/PCs. (A) There was no significant change in pAkt or actin in NS/PCs within the first hour after addition of $100 \mathrm{nM}$ of HU210 to culture medium. (B) Application of $100 \mathrm{nM}$ of HU210 rapidly induced phosphorylation of $\mathrm{pERK} 1 / 2$ in NS/PCs in the presence of bFGF and EGF in culture medium. (C) Application of $100 \mathrm{nM}$ of HU210 3 hours after removal of bFGF and EGF from culture medium also induced phosphorylation of pERK1/2 in NS/PCs. (D) Application of the ERK signaling inhibitor U0126 blocked the promoting effects of $100 \mathrm{nM}$ of HU210 on phosphorylation of pERK1/2 in NS/PCs 5 minutes after addition of HU210 to culture medium. (E) Addition of $\mathrm{U} 0126(10 \mu \mathrm{M})$ to the culture medium 1 hour before HU210 antagonized the promoting effects of $10 \mathrm{nM}$ to $1 \mu \mathrm{M}$ of HU210 on NS/PC proliferation. Error bars represent SEM. ${ }^{*} P<0.05$ and ${ }^{* *} P<0.01$ by Tukey post-hoc tests after 1 -way ANOVA. tERK1/2, total ERK1/2.

hoc tests, $P<0.01$ between control and each of the 3 concentrations of HU210), which was completely blocked by $100 \mathrm{ng} / \mathrm{ml}$ of pertussis (1-way ANOVA for repeated measures, $F_{1,18}=41.64, P<0.01$; pairwise comparisons, HU210-treated cells with or without pertussis: $P<0.01$ ) (Figure $2 \mathrm{E}$ ). It has been shown that HU210 activates $\mathrm{G}_{\mathrm{s}}$ proteins when $\mathrm{G}_{\mathrm{i} / \mathrm{o}}$ proteins are inhibited by pertussis toxin (27). Therefore, to determine whether the blockade effects of HU210induced NS/PC proliferation following pertussis treatment is achieved by activation of $\mathrm{G}_{\mathrm{s}}$ proteins, we examined the effects of cholera toxin, a $\mathrm{G}_{\mathrm{s}}$ protein activator, on NS/PC proliferation. Incubation of NS/PCs with $1 \mathrm{mg} / \mathrm{ml}$ of cholera toxin stimulated about 14-, 80-, 90-, and 13-fold increase in cAMP accumulation in NS/PCs $0.5,1,2$, and 24 hours after the addition of cholera toxin; cAMP production returned to the basal levels 48 hours after cholera toxin (1-way ANOVA, $F_{5,18}=93.341, P<0.01$ ) (Figure $2 \mathrm{~F}$ ). These results indicate the effective activation of $G_{s}$ proteins in NS/PCs by cholera toxin. However, there was no significant change in NS/PC proliferation $0.5,1,2,24$, and 48 hours after the addition of cholera toxin (1-way ANOVA, $F_{5,18}=76.562, P=0.86$ ) (Figure $2 \mathrm{G}$ ). These results together suggest the involvement of $\mathrm{G}_{\mathrm{i} / \mathrm{o}}$ proteins, but not $\mathrm{G}_{\mathrm{s}}$ proteins, in HU210-induced NS/PC proliferation.

Since $G_{i / o}$ protein activates PI3K/Akt and ERK signaling (29), which are well known to play an important role in cell growth and cell death, we studied whether HU210 could activate Akt and ERK1/2. There was no significant change in phosphorylation of phospho-Akt during the first 1 hour after HU210 application $\left(F_{4,10}=1.693, P=0.228\right)$ (Figure $\left.3 \mathrm{~A}\right)$, indicating that the PI3K/Akt signaling pathway is not involved in the action of HU210 on
NS/PC proliferation. In contrast, changes in phosphorylation of phospho-ERK1/2 (pERK1/2) during the first 1 hour after HU210 application were dramatic at specific time points, as shown by 1 -way ANOVA (with growth factors, $F_{4,15}=33.698, P<0.01$; without growth factors, $F_{4,15}=23.513, P<0.01$ ). As early as 5 minutes after addition of HU210 to culture medium with (Figure $3 \mathrm{~B}$ ) or without bFGF and EGF (Figure 3C), a 2.5-fold increase in phosphorylation of pERK1/2 was observed $(P<0.05)$. At 15 minutes after HU210 application, phosphorylation of pERK1/2 reached the peak level, which was about a 4-fold (with growth factors) or 7 -fold increase (without growth factors) relative to control $(P<0.01)$. By 60 minutes after addition of HU210, phosphorylation of pERK1/2 either significantly decreased $(P<0.05)$ (Figure 3B) or returned to the pretreatment level (Figure $3 \mathrm{C}$ ). We did not observe any significant changes in the total ERK $1 / 2$ during the first 1 hour after HU210 application. Thus, the significant increase in pERK1/2 in this period suggests an important involvement of ERK signaling pathway in the action of HU210 in promoting NS/PC proliferation. This hypothesis was supported by further experiments in which U0126, a specific inhibitor of the ERK pathway, was employed. Figure 3D shows an overall significant difference in pERK1/2 phosphorylation after application of vehicle or $100 \mathrm{nM}$ of HU210 with or without $10 \mu \mathrm{M}$ of $\operatorname{U0126}\left(F_{3,8}=60.769\right.$, $P<0.01)$. Specifically, HU210 profoundly increased phosphorylation of pERK1/2 $(P<0.01)$, which was almost completely blocked by U0126 $(P<0.01)$. A parallel experiment demonstrated that U0126 blocked the promoting effects of $100 \mathrm{nM}$ of HU210 on NS/PC proliferation (1-way ANOVA for repeated measures, 
A

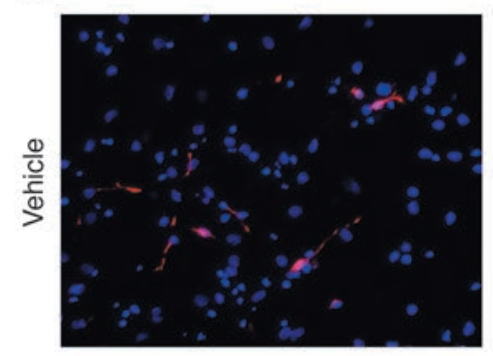

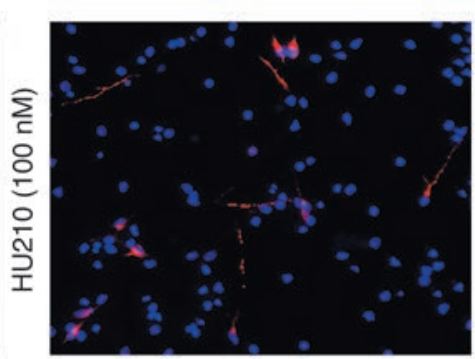

B

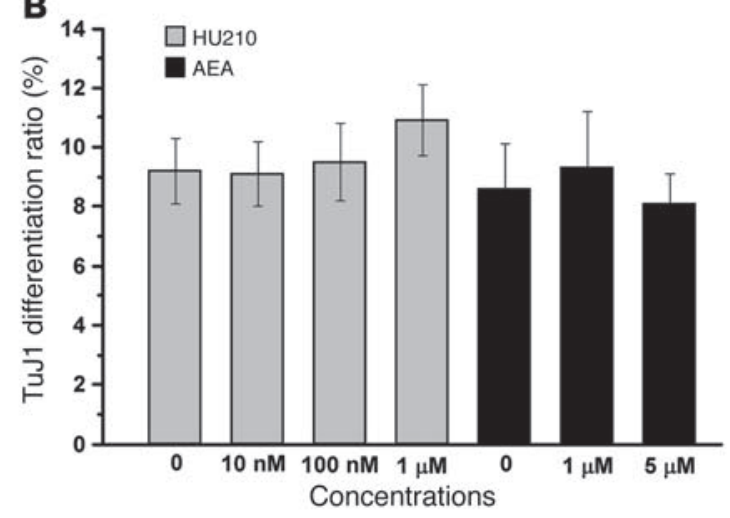

Figure 4

Effects of HU210 and AEA on neuronal differentiation of cultured hippocampal NS/PCs. (A) Incubation of NS/PCs with the culture medium containing either vehicle or $100 \mathrm{nM}$ of HU210 without growth factors for 8 days produced similar density of neurons (pink cells) stained with TuJ1 antibody. The total cultured cells are labeled deep blue by Hoechst staining. (B) There was no significant difference in the ratio of TuJ1-labeled neurons to total cells following application of HU210 $(10 \mathrm{nM}$ to $1 \mu \mathrm{M})$ or AEA (1 or $5 \mu \mathrm{M})$ to culture medium.

$F_{1,17}=6.356, P<0.05$; pairwise comparisons, HU210-treated cells with or without U0126: $P<0.05$ ) (Figure 3E).

HU210 and AEA do not affect neuronal differentiation of cultured NS/PCs. To examine the effects of HU210 on neuronal differentiation of cultured NS/PCs, neurospheres were dissociated, plated, and cultured in the medium containing bFGF and EGF for 1 day and then in another medium containing different concentrations of HU210 without bFGF or EGF for 8 days. After fixation, immunofluorescence staining was performed using antibodies against the neuronal marker $\beta$-tubulin III (TuJ1), followed by Hoechst staining that detects all the cultured cells. Cell counting revealed no significant difference among the ratios of TuJ1-labeled neurons and Hoechst-labeled total cells following treatment with vehicle or $10 \mathrm{nM}, 100 \mathrm{nM}$, or $1 \mu \mathrm{M}$ of HU210 (1-way ANOVA, $F_{4,20}=3.307, P=0.324$ ) (Figure 4), suggesting that HU210 exerts no significant effects on neuronal differentiation of cultured NS/PCs. Similarly to HU210, AEA ( 1 and $5 \mu \mathrm{M})$ did not produce significant effects on neuronal differentiation of cultured NS/PCs (1-way ANOVA, $F_{2,9}=0.177, P=0.840$ ) (Figure 4B).

Increased hippocampal cell proliferation following HU210 treatment in adult rats. BrdU labeling of dividing cells was used to test the acute effects of HU210 treatment on cell proliferation in adult hippocampus. Adult rats received a single dose of vehicle, AM281 $(3 \mathrm{mg} / \mathrm{kg}$, i.p.), or HU210 (25 or $100 \mu \mathrm{g} / \mathrm{kg}$, i.p.), followed 2 hours later by BrdU administration and then perfusion 1 day later. BrdU-labeled cells showed fusiform or irregular shape and were clustered or aggregated in the SGZ (Figure 5A) throughout the whole hippocampus in all rats examined. Cell counting revealed no significant change in the number of BrdU-positive cells in the SGZ among rats treated with vehicle, AM281, or HU210 (1-way ANOVA, $F_{3,16}=52.784, P=0.58$; $n=5$ ) (Figure 5B). We then examined the effects of chronic HU210 injection on cell proliferation in adult hippocampus. Two hours after receiving the last dose of twice-daily injections of vehicle, AM281 (3 mg/kg, i.p.), or HU210 (25 or $100 \mu \mathrm{g} / \mathrm{kg}$, i.p.) for 10 days, adult Long-Evans rats received BrdU administration and then were perfused 1 day later. Immunohistochemical staining showed an apparent increase in the density of BrdU-labeled cells in the SGZ following chronic administration of $100 \mu \mathrm{g} / \mathrm{kg}$ of HU210 (Figure 5C). One-way ANOVA revealed a significant overall difference in the mean \pm
SEM number of BrdU-positive cells in the SGZ $\left(F_{3,16}=11.504, P<0.001\right.$; $n=5$ ) (Figure 5D). Tukey post-hoc test showed a significant increase (about 40\%) in the number of BrdU-labeled cells following $100 \mu \mathrm{g} / \mathrm{kg}$ of HU210 $(P<0.05)$ but not $25 \mu \mathrm{g} / \mathrm{kg}$ of HU210 $(P=0.979)$, relative to vehicle (Figure 5D). AM281 injection seemingly decreased the number of BrdU-positive cells in the SGZ, but there was no significant difference relative to control $(P=0.099)$.

Increased newborn hippocampal neurons following chronic HU210 treatment in adult rats. A recent study has demonstrated that newborn neurons in the dentate granule cell layer that had survived 4 weeks were stably integrated into the granule cell layer (30). To examine the survival, migration, and differentiation of HU210-induced newborn cells in the SGZ, we injected rats twice daily with HU210 $(100 \mu \mathrm{g} / \mathrm{kg}$, i.p.), AM281 (3 mg/kg), or vehicle for 10 days, followed 12 hours later by $4 \mathrm{BrdU}$ injections at 12 hours intervals. One month after the last HU210, AM281, or vehicle injection, the majority of BrdU-labeled cells migrated and dispersed into the granule cell layer and showed size and morphology indistinguishable from both their neighboring granule neurons and from different treatment (Figure 6A). The number of BrdU-labeled dentate cells in HU210-treated rats was significantly higher than that in vehicletreated rats (Student's $t$ test, $P<0.01 ; n=5$ ) (Figure 6B), indicating that most of chronic HU210-induced newborn cells survived. Immunofluorescence staining revealed that HU210- and vehicletreated rats exhibited a similar proportion of BrdU/neuronal nuclear antigen (BrdU/NeuN) double-labeling cells to the total BrdUlabeled cells (Student's $t$ test, $P=0.977$ ) (Figure 6C), suggesting that chronic HU210-induced newborn cells in the SGZ have neuronal differentiation ratio similar to that of vehicle-induced newborn cells in the SGZ. Nevertheless, because chronic HU210 treatment significantly increased the number of BrdU-labeled newborn cells in the dentate gyrus (Figure 6B), the total number of newborn neurons doubly labeled with BrdU/NeuN in the dentate gyrus also significantly increased following chronic HU210.

No hippocampal neuronal death following chronic HU210 treatment in adult rats. Ample evidence has illustrated the increased hippocampal neurogenesis following ischemia, epileptic status, enriched environment, or exercise (15). It is therefore possible that increased hippocampal neurogenesis following chronic HU210 
A
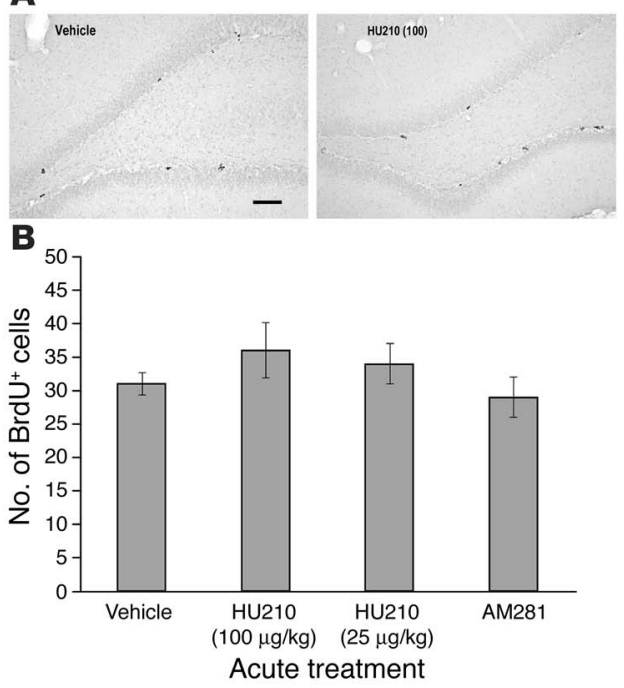

Figure 5

Effects of HU210 treatment on cell proliferation in the dentate gyrus in adult rats $(n=5-7$ rats in each group). Cell proliferation was assessed by BrdU labeling of dividing cells. (A) Representative microphotographs of the dentate gyrus show BrdU-positive cells clustered or aggregated in the SGZ in rats receiving an acute injection of vehicle or $100 \mu \mathrm{g} / \mathrm{kg}$ of HU210. Scale bar, $60 \mu \mathrm{m}$. (B) There was no significant difference in the average number of BrdU-stained cells in the dentate gyrus per section following 1 dose of acute vehicle, 100 and $25 \mu \mathrm{g} / \mathrm{kg}$ of HU210, and $3 \mathrm{mg} / \mathrm{kg}$ of AM281. (C) Representative microphotographs of the dentate gyrus show that twice-daily injections of $100 \mu \mathrm{g} / \mathrm{kg}$ of HU210 for 10 days apparently increased the density of BrdU-positive cells in the SGZ relative to chronic vehicle injection. Scale bar, 60 um. (D) Relative to vehicle injection, there was a significant increase in the number of BrdU-immunoreactive cells in the dentate gyrus following chronic treatment with $100 \mu \mathrm{g} / \mathrm{kg}$ of HU210, but not $25 \mu \mathrm{g} / \mathrm{kg}$ of HU210 or $3 \mathrm{mg} / \mathrm{kg}$ of AM281. Error bars represent SEM. ${ }^{*} P<0.05$ by Tukey post-hoc tests after 1 -way ANOVA.
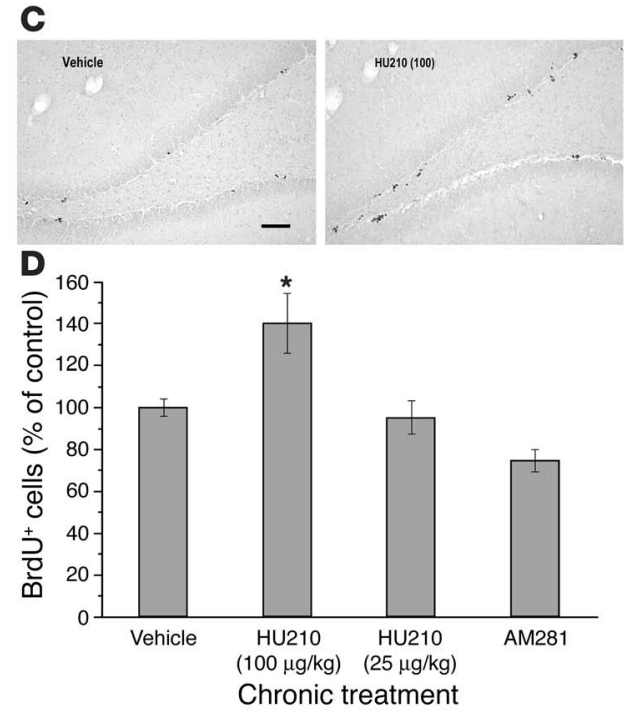

hippocampal neurogenesis (18). Therefore, we employed the same behavioral tests to examine the effects of chronic HU210 treatment on measures of anxiety and depression. Rats received twicedaily injections of vehicle, AM281 (3 mg/kg), or HU210 (100 $\mu \mathrm{g} / \mathrm{kg})$ for 10 days, followed 12 hours later by $4 \mathrm{BrdU}$ injections at 12 hour intervals. Rats were subjected to behavioral testing 1 month later, based on the recent finding that hippocampal newborn neurons need 4 weeks to become functional (32). In the NSF test, 1-way ANOVA showed an overall significant difference in the latency to eat in the novel environment among the 3 groups of rats deprived of food for 48 hours $\left(F_{2,20}=8.187, P<0.01\right)$. As shown in Figure 8A, relative to vehicle treatment, chronic HU210 (but not AM281) treatment significantly reduced the latency to eat food in the novel environment $(P<0.01)$. However, when returned to their home cages immediately after the test, rats receiving vehicle, chronic AM281, and chronic HU210 showed no significant diftreatment in adult rats may result from the toxic effects of chronic HU210 treatment on hippocampal neurons. To explore this possibility, we examine the total number of the dentate granule and CA3 pyramidal neurons following twice-daily injections of HU210 $(100 \mu \mathrm{g} / \mathrm{kg})$ for 10 days. As depicted in Figure 7A, HU210-treated rats did not show detectable loss of NeuN-immunopositive neurons in the hippocampus, relative to naive control rats. Stereological cell counting confirmed that no significant difference in the total number of the dentate granule cells $\left(F_{1,4}=1.443, P=0.782\right)$ and CA3 pyramidal neurons $\left(F_{1,4}=5.099, P=0.553\right)$ between naive and HU210-treated rats (Figure 7B). These results, however, do not exclude the possibility that some of NeuN-stain neurons following chronic HU210 treatment shown in Figure 7A are dying. Accordingly, we used TUNEL stain and Fluoro-Jade B stain to examine the degenerating hippocampal neurons (31) in rats receiving chronic HU210 treatment, with the naive rats as negative control and kainic acid-treated rats as positive control (31). We failed to detect any TUNEL- or Fluoro-Jade B-stained degenerating cells throughout the whole hippocampus in both naive rats and HU210-treated rats, whereas kainic acid-injected rats showing epileptic status exhibited numerous dying cells in the CA3 pyramidal cell layer and even dentate granule cell layer (Figure 7, C and D).

Anxiolytic and antidepressant effects of chronic HU210. Two recent studies employing novelty-suppressed feeding (NSF) tests and forced swimming test (FSTs) as measures of anxiety and depression have shown that chronic treatment with the antidepressant fluoxetine produced anxiolytic and antidepressant effects $(18,19)$, and the anxiolytic effects are likely achieved by promoting ference in the latency to eat food $\left(F_{2,20}=0.276, P=0.762\right)$ (Figure 8A) or the amount of food consumed $\left(F_{2,20}=0.839, P=0.447\right)$. In the FST, there was an overall significant difference in the duration of immobility among vehicle-, AM281-, and HU210-treated rats $\left(F_{2,19}=4.441, P<0.05\right)$. Post-hoc test revealed that HU210 (but not AM281) significantly decreased immobility $(P<0.05)$ (Figure $8 B$ ), whereas neither AM281 nor HU210 produced significant effects on the number of rats climbing in the first 5 minutes in the pretest sessions of the FST $\left(F_{2,19}=7.552, P=0.887\right)$ (Figure 8C). Rats were killed for immunohistochemical staining after behavioral tests. The majority of BrdU-positive cells in vehicle-, AM281-, or HU210treated rats were located in the granule cell layer, suggesting that they became granule neurons. Cell counting revealed an overall significant difference in the number of BrdU-stained cells in the dentate gyrus $\left(F_{2,19}=3.896, P<0.05\right)$. Post-hoc test showed results similar to those in Figure 5D: namely, relative to vehicle-treated rats, HU210-treated rats displayed a significant increase $(P<0.05)$ in the number of BrdU-positive cells in the dentate gyrus, whereas AM281-treated rats exhibited no significant difference $(P=0.165)$. Thus, these data together suggest that chronic HU210 treatment promoted hippocampal neurogenesis and exerted anxiolytic- and antidepressant-like effects.

Association of hippocampal neurogenesis with anxiolytic- and antidepressant-like effects of chronic HU210. To determine the relationship between hippocampal neurogenesis and anxiolytic- and antidepressant-like effects produced by chronic HU210, we examined the effects of a selective destruction of the hippocampal neural stem cells on the behavioral effects of chronic HU210. During the 

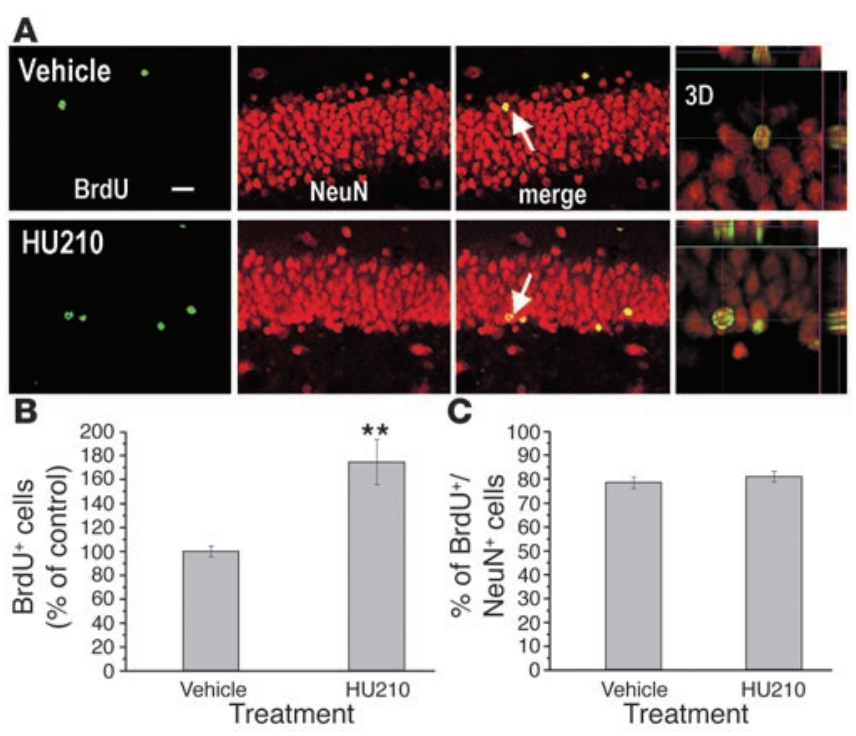

course of receiving chronic HU210 injections, 1 group of LongEvans rats received two 5-Gy doses of $\mathrm{x}$-rays confined to a limited brain region including the hippocampus, as previously described (18). Four BrdU injections with 12-hour intervals were given after the last HU210 injection. Hippocampal irradiation produced a prominent decrease in the number of BrdU-positive cells in the $\operatorname{SGZ}\left(F_{2,12}=6.011, P<0.01\right)$ (Figure $\left.8 \mathrm{D}\right)$ and a blockade of chronic HU210-induced anxiolytic-like effects $\left(F_{2,12}=4.209, P<0.05\right)$ (Figure $8 \mathrm{E})$ and antidepressant-like effects $\left(F_{2,12}=9.100, P<0.05\right)$ (Figure 8F) without significant effects on amount of food consumed when rats were returned to their home cages $\left(F_{2,12}=2.376\right.$ $P=0.502)$ (Figure $8 \mathrm{E})$ and climbing times $\left(F_{2,12}=9.113, P=0.624\right)$. Because two 5-Gy doses of $x$-rays were not found to alter the morphology and function of mature neurons in the hippocampus, hypothalamus, and amygdala (18), our results together suggest that chronic HU210 treatment reduced anxiety and depression, likely via promoting hippocampal neurogenesis.

\section{Figure 6}

Fate and migration of BrdU-labeled cells in the dentate gyrus following chronic HU210 treatment. After receiving twice-daily injections of vehicle or $100 \mu \mathrm{g} / \mathrm{kg}$ of HU210 for 10 days, rats were given $4 \mathrm{BrdU}$ injections, followed 1 month later by perfusion. (A) Representative confocal microscopic images show costaining (yellow) of BrdU (green) and NeuN (red) in the dentate granule cell layer. The majority of BrdUstained cells are doubly labeled with the neuronal marker NeuN and located within the granule cell layer. 3D, 3 dimensional photograph of doubly stained neurons indicated with arrows. Scale bar, $20 \mu \mathrm{m}$. (B) Chronic HU210 significantly increased the number of BrdU-stained cells in the dentate gyrus ( $n=5$ in each group). (C) There was no significant difference in the proportion of cells doubly labeled with BrdU and NeuN to the total cells singly labeled with BrdU. Error bars represent SEM. ${ }^{* *} P<0.01$ by Student's $t$ test.

\section{Discussion}

Natural selection has conserved cannabinoid receptors in various vertebrates and invertebrates that have been evolutionarily separate for 500 million years (33), indicating the importance of cannabinoid receptors to life. A recent study has shown CB1-immunoreactive newborn neurons in the adult rat hippocampus 1 week after BrdU injection (24). Here we have observed that approximately $95 \%$ of cultured neurosphere cells were doubly labeled with CB1 and nestin, a marker for NS/PCs. Western blotting and PCR further showed the expression of CB1 protein and gene in NS/PCs. We also detected cells doubly stained with CB1 and BrdU in the SGZ of adult rats that were sacrificed 2 hours after receiving a single dose of BrdU. This time interval allowed us to label mitotically active cells (i.e., NS/PCs) in the hippocampal SGZ, as they have a doubling time of 11-25 hours (14). Therefore, this study provides the first evidence suggesting that both embryonic and adult hippocampal NS/PCs express CB1 receptors.

Accordingly, we hypothesized that cannabinoids could regulate proliferation of hippocampal NS/PCs by acting on CB1 receptors. This hypothesis is supported by our subsequent findings that both the synthetic cannabinoid HU210 and endocannabinoid AEA profoundly promoted embryonic hippocampal NS/PC proliferation, and the effects of HU210 could be blocked by the selective

\section{Figure 7}

Effects of chronic HU210 on neuronal survival. (A) Both naive control rats and rats receiving twice-daily injections of HU210 $(100 \mu \mathrm{g} / \mathrm{kg})$ for 10 days showed similar density of NeuN-stained neurons in the dentate granule cell layer and CA3 pyramidal cell layer. (B) There was no significant difference in the total number of NeuN-stained cells in the dentate granule cell layer and CA3 pyramidal layer between naive and HU210-treated rats $(n=3$ for each group). (C) While naive rats and chronic HU210treated rats showed no TUNEL-stained cells in the hippocampus, kainic acid-treated (KA-treated) rats exhibited numerous TUNEL-positive neurons in the CA3 pyramidal cell layer and dentate granule cell layer. (D) While naive rats and chronic HU210-treated rats showed no FluoroJade B-stained (FJB-stained) cells in the hippocampus, kainic acid-treated rats exhibited numerous Fluoro-Jade B-positive neurons in the CA3 pyramidal cell layer $(n=3$ for each group). Scale bar, $60 \mu \mathrm{m}$.
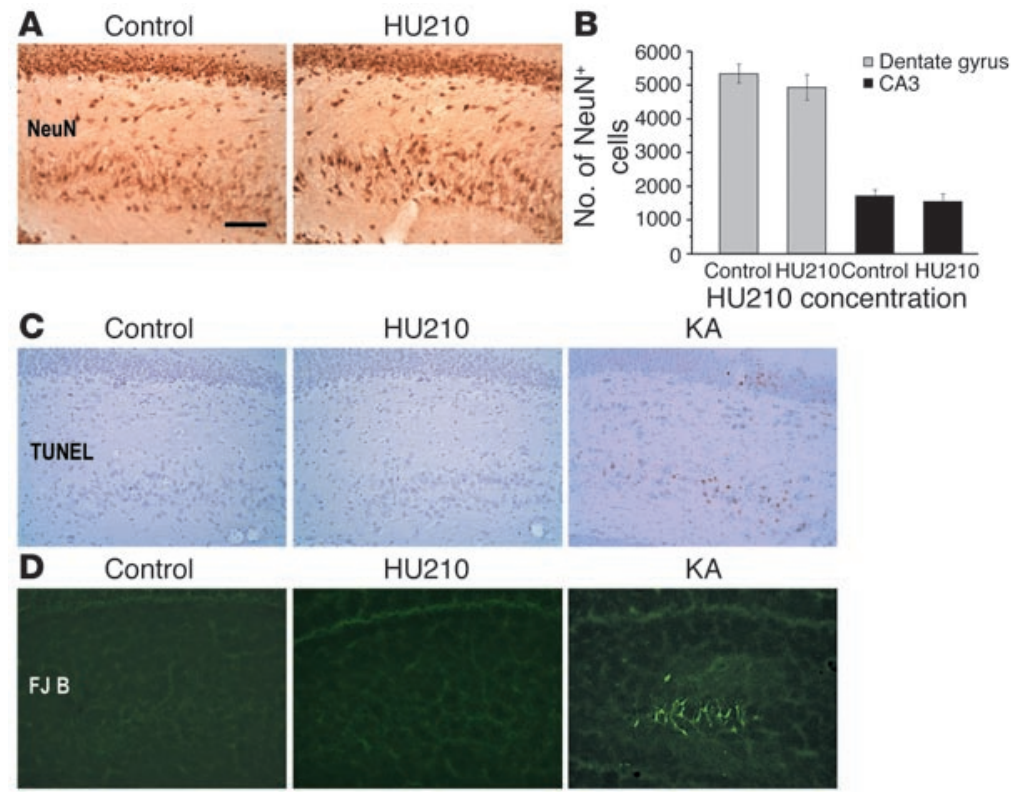

HU210

$\mathrm{KA}$

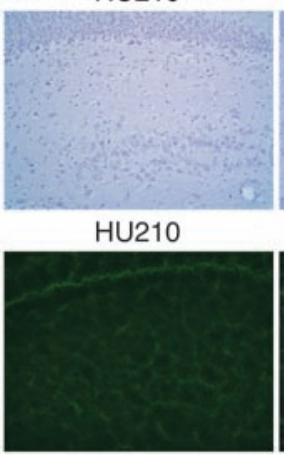



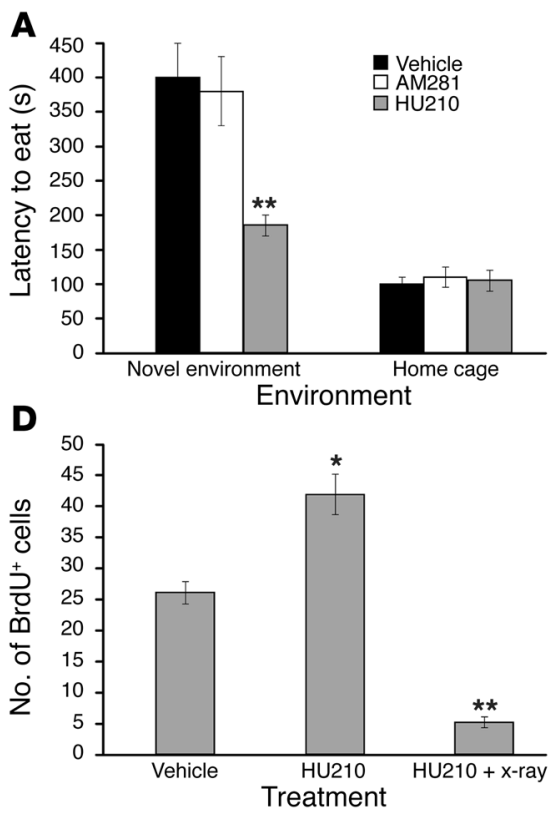

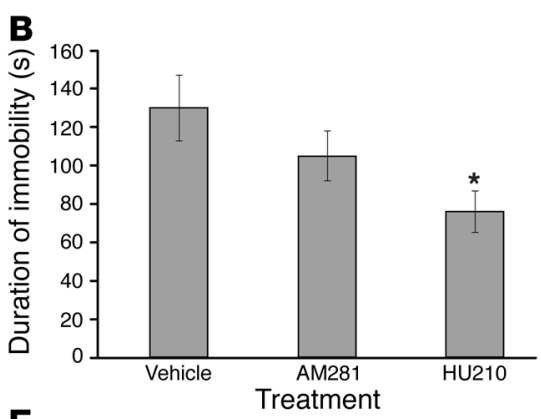

E

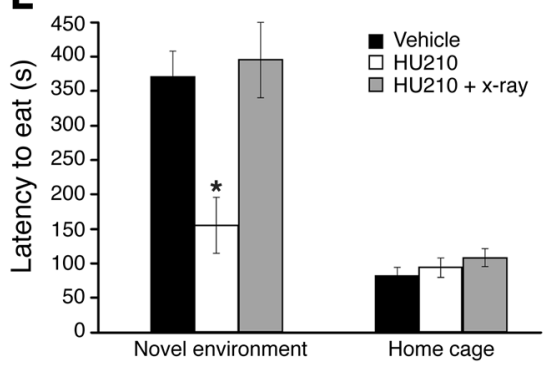

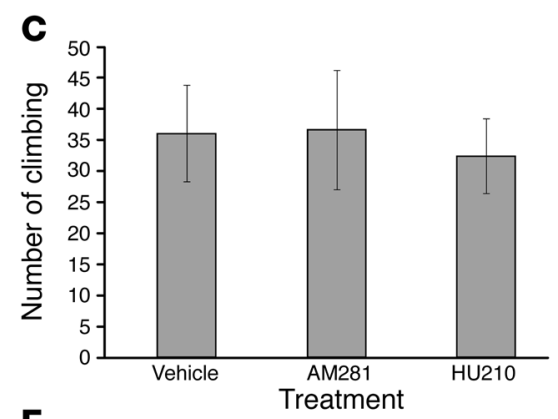

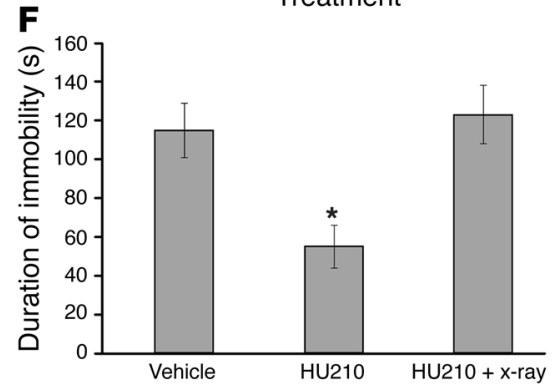

\section{Figure 8}

Effects of chronic HU210 on the NSF test, the FST, and cell proliferation in the dentate gyrus. After receiving chronic vehicle, AM281, or HU210 injections for 10 days, rats were injected with BrdU to label dividing cells, followed 1 month later by behavioral testing and 1 day later by perfusion ( $n=7-8$ for each group in A-C; $n=5$ for each group in D-F). (A) In the NSF test, rats receiving chronic HU210 (but not AM281) showed significantly shortened latency to feed in a novel environment but not in their home cages, suggesting anxiolytic effects produced by HU210. (B) In the FST, chronic HU210 (but not AM281) significantly shortened the duration of immobility (i.e., antidepressant-like effects). (C) Among the rats receiving vehicle, AM281, and HU210, there was no significant difference in the number climbing in the first 5 minutes in the pretest sessions of the FST. (D) Irradiation of the hippocampus prominently reduced cell proliferation in the SGZ. (E) Irradiation of the hippocampus blocked chronic HU210-induced shortened latency of rats to feed in novel environment but not in their home cages in the NSF test. (F) Irradiation of the hippocampus prevented chronic HU210-induced shortened duration of immobility in the FST. Error bars represent SEM. ${ }^{*} P<0.05$ and ${ }^{* *} P<0.01$ by Tukey post-hoc tests after 1-way ANOVA.

CB1 receptor antagonist AM281. Furthermore, we discovered the mitogenic effects of HU210 on cultured NS/PCs in the absence of FGF-2 and EGF in the culture medium, thus excluding the possibility that HU210 induces NS/PC proliferation via indirect action through FGF-2 and EGF and reiterating the direct action of HU210 on CB1 receptors on the cultured NS/PCs. We next observed that HU210 promoted NS/PC proliferation, likely via $\mathrm{G}_{\mathrm{i} / \mathrm{o}}$ protein activation and subsequent ERK signaling. Although both HU210 and AEA exerted no significant effects on neuronal differentiation of NS/PCs, they significantly increased NS/PC proliferation, leading to increased total number of newborn neurons. Similar results were also obtained in freely moving adult rats. That is, chronic, but not acute, HU210 significantly increased the number of newborn hippocampal neurons in adult rats by promoting NS/PC proliferation but not differentiation. We also provided evidence indicating that the promoting effects of chronic HU210 treatment on adult hippocampal neurogenesis are not the outcome of hippocampal neuronal death, as we did not detect neuronal loss or dying hippocampal neurons following chronic HU210 injection. Overall, these data support the idea that cannabinoids are able to promote embryonic and adult hippocampal neurogenesis via the $\mathrm{CB} 1$ receptors in the NS/PCs.

Our findings of cannabinoid-induced increase in hippocampal neurogenesis are in agreement with the recent observation that CB1 receptor-knockout mice display profound suppression of hippocampal neurogenesis (24). However, our observation that both HU210 and AEA did not affect neuronal differentiation of embryonic hippocampal NS/PCs is different from Rueda et al.'s study showing that endocannabinoids and HU210 inhibited neuronal differentiation of cultured embryonic cortical and human NS/PCs and PC12 cells stably transfected with human CB1, which was blocked by CB1 receptor antagonist (25). These differing results may be due to the differing effects of cannabinoids on embryonic cortical and hippocampal NS/PCs. In in vivo experiments, Rueda et al. demonstrated that chronic administration of endogenous cannabinoid for 2 weeks increased the number of newborn (BrdU-immunopositive), non-neuronal (NeuNimmunonegative) cells in the rat dentate gyrus without affecting the total number of BrdU-labeled cells (25), which was interpreted as evidence for a CB1-mediated impairment in neurogenesis. We observed, however, a significant increase in the hippocampal newborn neurons following twice-daily HU210 injection for 10 days. The differing regulatory effects of endocannabinoid shown in Rueda et al.'s study and exocannabinoid HU210 shown in this study on hippocampal neurogenesis may be produced by the different pharmacology of exo- and endocannabinoids in the brain, i.e., the full and partial agonist actions of exo- and endocannabinoids on CB1 receptors, respectively (11); or the different intracellular signaling pathways induced by exo- and endocannabinoids as speculated by Martin et al. (34); or the opposing effects induced by high and low doses of exocannabinoids (35) and endocannabinoids (36). In fact, some studies have shown 
that exo- and endocannabinoids have differential or opposing effects in many areas, including nociception (37), the vascular system (38), and epilepsy (39).

Following the observation that chronic HU210 treatment promoted neurogenesis in the dentate gyrus, we wondered whether chronic HU210-induced newborn neurons are of functional significance. Given the recent findings that chronic fluoxetine treatment produced antidepressant and anxiolytic effects $(18,19)$ and the anxiolytic effects are likely achieved by promoting hippocampal neurogenesis (18), we hypothesized that chronic HU210-induced hippocampal neurogenesis may also correlate with anxiolytic and antidepressant effects. Our subsequent experiments supported this hypothesis. After 1 month of chronic HU210 treatment, rats deprived of food for 48 hours showed significantly reduced latency to eat food in a novel environment, suggesting that chronic HU210 treatment exerted anxiolytic effects. These results are consistent with a recent study showing that once-daily injections of the cannabinoid receptor agonist CP55,940 for 11 days reduced anxiety in the elevated plus-maze test performed 30 days after the last CP55,940 injection (40). Chronic HU210-induced shortened latency to eat food in the novel environment is unlikely due to the well-known effects of HU210 on appetite (1), because chronic HU210 treatment produced no significant effects on the latency to eat food or the amount of food consumed when rats were returned to the familiar environment of their home cages immediately after the test. One week after undergoing NSF testing, the same rats receiving chronic HU210 treatment showed a significantly reduced duration of immobility in the FST, indicating that chronic HU210 also exerts antidepressant effects. Because acute cannabinoid treatment profoundly affects motor function of humans and animals $(1,10)$, chronic HU210-induced shortened immobility in the FST may be produced by its action in changing the motor activity of rats. This is unlikely, however, as we observed no significant difference in the number of rats climbing $(41,42)$ among HU210-, AM281-, and vehicle-treated groups in the first 5 minutes of the pretest sessions of the FST. The anxiolytic- and antidepressant-like behavioral changes in rats 1 month after chronic HU210 treatment are unlikely to have been produced by the cannabinoid withdrawal effects, since, as shown in our recent study (8), rodents receiving chronic cannabinoid would display detectable cannabinoid withdrawal syndrome only after administration of CB1 receptor antagonists. Finally, the same rats with reduced measures of anxiety and depression following chronic HU210 treatment showed significantly increased numbers of BrdU-labeled cells within the dentate granule cell layer. These overall results thus confirmed our above-described novel findings that chronic HU210 treatment significantly increased newborn neurons in the hippocampal dentate gyrus (Figure 6). The lack of statistically significant effects produced by the CB1 antagonist AM281 on both hippocampal neurogenesis and behavioral testing suggests that daily temporary blockade of CB1 receptors is not strong enough to affect hippocampal neurogenesis and the regulation of anxiety or depression.

Multiple classes of antidepressant drugs increase hippocampal neurogenesis in a chronic but not acute time course, which corresponds to the therapeutic time course necessary for effects (12, 43). Conversely, cell proliferation is decreased in animal models of depression or stress and anxiety paradigms $(12,43)$. Further evidence supporting the association of hippocampal neurogenesis with mood and anxiety disorders comes from a recent study. In this study the disruption of antidepressant-induced hippocampal neurogenesis by $\mathrm{x}$-irradiation of a restricted mouse brain region containing the hippocampus blocked anxiolytic effects of several antidepressants (18). We observed similar results in the present study that $\mathrm{x}$-irradiation of a brain region containing the hippocampus blocked both the adult hippocampal neurogenesis and anxiolytic- and antidepressant-like effects of chronic HU210. Thus, all these lines of evidence support the notion that chronic HU210 treatment produces anxiolytic- and antidepressant-like effects via promoting hippocampal neurogenesis.

It has been shown that acute, high doses of CB1 agonists or cannabinoids produced anxiety-like effects in rats (44-49) or depression-like effects in mice $(50,51)$. We observed here that chronic administration of high, but not low, doses of HU210 exerts anxiolytic- and antidepressant-like effects. To make things more complicated, acute, low doses of cannabinoids have been found to induce anxiolytic-like effects in rodents $(44,49,52,53)$. These complicated effects of high and low doses of acute and chronic exposure to cannabinoids may explain the seemingly conflicting results observed in clinical studies regarding the effects of cannabinoid on anxiety and depression $(3,4,10)$.

In summary, since adult hippocampal neurogenesis is suppressed following chronic administration of opiates (20), alcohol (21), nicotine (22), and cocaine (23), the present study suggests that cannabinoids are the only illicit drug that can promote adult hippocampal neurogenesis following chronic administration. Increased hippocampal neurogenesis appears to underlie the mechanism of anxiolytic- and antidepressant-like effects produced by a high dose of chronic HU210 treatment. The opposing effects of high doses of acute and chronic cannabinoids, together with the anxiolytic-like effects caused by a low dose of cannabinoids, may finally explain discrepancies in the clinical study literature regarding the effects of cannabinoid on anxiety and depression.

\section{Methods}

All procedures were in accordance with the guidelines established by the Canadian Council on Animal Care and approved by the University of Saskatchewan Animal Care Committee.

Primary NS/PC culture. NS/PCs were isolated and propagated using a neurosphere method developed by Reynolds and Weiss (54) and modified by Gritti et al. (55). Hippocampi were dissected under a stereomicroscope from E17 Long-Evans rat embryos into HBSS without calcium or magnesium (Invitrogen Corp.). The tissues were then cut into small pieces, digested with $0.05 \%$ trypsin/ $0.53 \mathrm{mM}$ EDTA (Sigma-Aldrich) for 10 minutes at $37^{\circ} \mathrm{C}$ and triturated with a fire-polished pipette into individual cells. The cells were collected by centrifugation, resuspended in DMEM/F12 medium (1:1 mixture) (Invitrogen Corp.), and gently forced through a $41-\mu \mathrm{m}$ nylon net filter (Millipore) to form a suspension of disaggregated cells. The disaggregated cells were seeded into uncoated T25 culture flasks (TPP) at a density of $1 \times 10^{5}$ viable cells $/ \mathrm{ml}$ in DMEM/F12 medium supplemented with B27 supplement (Invitrogen Corp.), $20 \mathrm{ng} / \mathrm{ml} \mathrm{FGF-2} \mathrm{(Chemicon} \mathrm{Interna-}$ tional), and $20 \mathrm{ng} / \mathrm{ml} \mathrm{EGF}$ (Invitrogen Corp.). The cells were maintained in a humidified incubator at $37^{\circ} \mathrm{C}$ with $95 \%$ atmospheric air $/ 5 \% \mathrm{CO}_{2}$, grown as free-floating aggregates (neurospheres), and passaged every 5-6 days. All experiments were carried out using the second passage of NS/PCs.

NS/PC proliferation assay. Single-cell suspensions were prepared from neurospheres by enzymatic dissociation with trypsin-EDTA. The cells were then allowed to pass through a $40-\mu \mathrm{m}$ nylon net filter and plated in 96-well microplates at a density of $1 \times 10^{5}$ cells $/ \mathrm{ml}$, followed 12 hours later by the addition of reagents including $0,1 \mathrm{nM}, 10 \mathrm{nM}, 100 \mathrm{nM}, 1 \mu \mathrm{M}$, or $10 \mu \mathrm{M}$ of HU210 [(6aR)-trans-3-(1,1-dimethylheptyl)-6a,7,10,10a-tetrahy- 
dro-1-hydroxy-6,6-dimethyl-6H-dibenzo[b,d]pyran-9-methanol] (dissolved in $0.1 \%$ [vol/vol] of DMSO; Tocris Bioscience) or AM281 [1-(2,4-dichlorophenyl)-5-(4-iodophenyl)-4-methyl- $N$-4-morpholinyl-1H-pyrazole-3carboxamide] (dissolved in $0.1 \%$ [ $\mathrm{vol} / \mathrm{vol}]$ of DMSO; Tocris Bioscience), or $0,10 \mathrm{nM}, 100 \mathrm{nM}, 1 \mu \mathrm{M}, 10 \mu \mathrm{M}$, or $100 \mu \mathrm{M}$ of AEA [ $N$-(2-hydroxyethyl)-5Z,8Z,11Z,14Z-eicosatetraenamide] (dissolved in $0.1 \%$ [ $\mathrm{vol} / \mathrm{vol}]$ of ethanol; Sigma-Aldrich). The concentration range of HU210, AM281, and AEA was determined according to our pilot experiments. In separate experiments, $100 \mathrm{ng} / \mathrm{ml}$ of pertussis (Sigma-Aldrich) or $10 \mu \mathrm{M}$ of U0126 [1,4-diamino-2,3-dicyano-1,4-bis(2-aminophenylthio) butadiene] (Cell Signaling Technology) were added 4 hours and 1 hour, respectively, prior to the addition of different concentrations of HU210. The concentrations of pertussis and U0126 were chosen based on the previous findings that these concentrations effectively inhibited $\mathrm{G}_{\mathrm{i} / \mathrm{o}}$ protein and ERK signaling in cultured NS/PCs $(56,57)$. After incubating the microplate at $37^{\circ} \mathrm{C}$ in $5 \% \mathrm{CO}_{2} / 95 \%$ air for 48 hours, cell proliferation was measured using the WST-8 assay with Cell Counting Kit-8 (Dojindo Molecular Technologies Inc.) or BrdU incorporation assay with Cell Proliferation ELISA BrdU kit (Roche Diagnostics Corp.). In additional experiments, $1 \mathrm{mg} / \mathrm{ml}$ of cholera toxin (Sigma-Aldrich) was added, and 0, 0.5, 1, 2, 24, or 48 hours later, the culture medium containing cholera toxin was replaced with the regular culture medium. Cell proliferation was measured 48 hours after addition of cholera toxin using the WST- 8 assay. The concentration of cholera toxin was determined after a pilot experiment.

WST-8 assay. The number of viable cells was estimated using the WST- 8 assay, which provides effective and reproducible determination of the proliferative activity of NS/PCs (58). WST-8 [2-(2-methoxy-4-nitrophenyl)-3(4-nitrophenyl)-5-(2,4-disulfophenyl)-2H-tetrazolium, monosodium salt] is reduced by the mitochondrial enzyme NAD-dependent succinate dehydrogenase to form a colored formazan product, which is soluble in the culture medium. The amount of formazan dye generated by the activity of the dehydrogenases in cells is known to be directly proportional to the number of living cells. To measure the proliferative activity of NS/PCs in 96-well microplates, $10 \mu \mathrm{l}$ of the Cell Counting Kit solution were added into each well, followed by incubation of the microplates at $37^{\circ} \mathrm{C}$ in $5 \% \mathrm{CO}_{2} / 95 \%$ air for 5 hours. Absorbance was measured at $450 \mathrm{~nm}$ using a microplate reader (Molecular Devices) with a reference wavelength of $650 \mathrm{~nm}$.

BrdU incorporation assay. The cells were labeled with $10 \mu \mathrm{M}$ of $\mathrm{BrdU}$ and incubated at $37^{\circ} \mathrm{C}$ in $5 \% \mathrm{CO}_{2} / 95 \%$ air for 4 hours. After centrifugation at $300 \mathrm{~g}$ for 10 minutes, the labeling medium was removed by aspiration and the cells were dried. Then, cellular DNA was denatured by adding $200 \mu \mathrm{l}$ of FixDenat solution into each well, and the microplates were incubated at room temperature for 30 minutes. After removal of the FixDenat solution, $100 \mu \mathrm{l}$ of anti-BrdU antibody conjugated with peroxidase solution was added to each well, followed by incubation of microplates at room temperature for 90 minutes. After 3 washes with washing solution, $100 \mu \mathrm{l}$ of substrate solution was added to each well, and the microplates were incubated at room temperature for 40 minutes. The reaction was then stopped by adding $25 \mu \mathrm{l}$ of $1 \mathrm{M} \mathrm{H}_{2} \mathrm{SO}_{4}$ solution into each well. Absorbance was measured at $450 \mathrm{~nm}$ using a microplate reader (Molecular Devices) with a reference wavelength of $650 \mathrm{~nm}$.

Measurement of cAMP levels in cultured NS/PCs. NS/PCs were incubated with $1 \mathrm{mg} / \mathrm{ml}$ of cholera toxin for $0,0.5,1,2,24$, or 48 hours, followed by preparation of samples for the measurement of cAMP production using the Direct cAMP Enzyme Immunoassay Kit (Sigma-Aldrich) according to manufacturer's manual.

Immunocytochemistry for cultured NS/PCs. To detect CB1 receptor in cultured hippocampal NS/PCs, neurospheres were plated on 12-mm glass coverslips coated with $15 \mu \mathrm{g} / \mathrm{ml}$ of poly-L-ornithine and were cultured in DMEM/F12 medium supplemented with B27 supplement, $20 \mathrm{ng} / \mathrm{ml}$
FGF-2, and $20 \mathrm{ng} / \mathrm{ml} \mathrm{EGF}$ for 24 hours. Cells on coverslips were fixed with $4 \%$ paraformaldehyde, rinsed in PBS, and blocked with 5\% normal goat serum for 60 minutes. Then, cells were incubated in a cocktail solution containing goat anti-CB1 antibody (1:500; Santa Cruz Biotechnology Inc.) and mouse anti-nestin antibody (1:2,000; Chemicon International) at $4{ }^{\circ} \mathrm{C}$ overnight. The cells were washed in PBS 3 times and incubated in another cocktail solution containing Alexa Fluor 488-conjugated rabbit anti-mouse $\operatorname{IgG}(1: 400)$ and Alexa Fluor 568--conjugated rabbit anti-goat $\operatorname{IgG}(1: 400)$ secondary antibodies (Invitrogen Corp.) at room temperature for 3 hours. Cell nuclei were stained in PBS containing $5 \mu \mathrm{g} / \mathrm{ml}$ of Hoechst 33258 (Sigma-Aldrich) at room temperature for 20 minutes. The coverslips were washed and mounted with antifade medium (DakoCytomation). Immunohistochemical controls for CB1 antibody were performed using antiserum preabsorbed with the immunogen $(1.0 \mathrm{mg} / \mathrm{ml})$.

For differentiation experiments, dissociated cells were plated on $12-\mathrm{mm}$ glass coverslips coated with $15 \mu \mathrm{g} / \mathrm{ml}$ of poly-L-ornithine within 24-well culture plate at a density of $3 \times 10^{4}$ cells per well and were cultured in DMEM/F12 medium supplemented with B27 supplement, $20 \mathrm{ng} / \mathrm{ml} \mathrm{FGF-2,} \mathrm{and} 20 \mathrm{ng} / \mathrm{ml}$ EGF for 12 hours. Then, the culture medium was changed to FGF-2- and EGF-free DMEM/F12 medium containing B27 supplement and HU210 (10 or $100 \mathrm{nM}$ or $1 \mu \mathrm{M})$ or AEA (1 or $5 \mu \mathrm{M})$. Cells were cultured further for 8 days, with complete change of culture medium and drugs once every 3 days. After fixation with $4 \%$ paraformaldehyde, cells were rinsed in PBS and incubated in $5 \%$ normal goat serum for 60 minutes before incubation in mouse anti-TuJ1 antibody (1:500; Sigma-Aldrich) at $4{ }^{\circ} \mathrm{C}$ overnight. The primary antibody was visualized by incubation of cells in Alexa Fluor 568-conjugated goat anti-mouse secondary antibody (1:400; Invitrogen Corp.) at room temperature for 3 hours. Cell nuclei were stained with Hoechst 33258 solution for 20 minutes. The number of TuJ1-positive cells and Hoechst-stained total cells was counted using a $40 \times$ objective lens on an Olympus BX-51 light microscope. Cell counting was conducted in 10 randomly chosen fields in each coverslip by an observer who had no knowledge of the treatment conditions.

Western blotting. NS/PCs were plated on $10-\mathrm{cm}$ culture dishes coated with $15 \mu \mathrm{g} / \mathrm{ml}$ of poly-L-ornithine at $1 \times 10^{6}$ cells/dish for 24 hours. Then, $100 \mathrm{nM}$ of HU210 or vehicle was added to the culture medium, and the cells were collected $0,5,15,30$, and 60 minutes later. Total cellular proteins were extracted with lysis buffer (1\% Triton X-100, 10\% glycerol, $20 \mathrm{mM}$ Tris-HCl, $\mathrm{pH}$ 7.4, 1 mM EDTA, $1 \mathrm{mM}$ sodium orthovanadate, $1 \mathrm{mM}$ sodium fluoride, and protease inhibitor mix). Equivalent amounts of extracted proteins $(20 \mu \mathrm{g})$ were resolved on $10 \%$ SDS-PAGE and electroblotted at $4{ }^{\circ} \mathrm{C}$ for 50 minutes to nitrocellulose membrane (Amersham Biosciences). After blocking the background staining with $5 \%$ (wt/vol) skim milk in PBS, the membranes were incubated in goat anti-CB1 antibody (1:500; Santa Cruz Biotechnology Inc.), rabbit anti-pAkt (1:1,000; Alpha Diagnostic International), mouse anti-pERK1/2 (1:1,000; Santa Cruz Biotechnology Inc.), and rabbit anti-total ERK1/2 (1:1,000; Cell Signaling Technology). Antibody against $\beta$-actin (1:1,000; Sigma-Aldrich) was used as an internal control for the concentration of protein loaded. Immunoreactive proteins were detected using HRP-conjugated secondary antibodies and an ECL kit (Amersham Biosciences) according to the manufacturer's instructions. Quantification of the immunoblots was performed by densitometric analysis of chemiluminescence-exposed films, using Image-Pro Plus software (version 4.1; Carsen Group). Immunohistochemical controls were performed by using antiserum preabsorbed with the immunogen $(1.0 \mathrm{mg} / \mathrm{ml})$.

PCR. NS/PCs were collected, and rat CB1 full encoding region was amplified in NS/PCs by PCR with primers (sense: $5^{\prime}$-TGGATCCATGAAGTCGATCCTAGATGGCC-3'; antisense: 5'-CGAATTCTCACAGAGCCTCGGCGGACGTG-3'). The amplification reaction was carried out in a PerkinElmer GeneAmp (PCR System 9600) for 30 cycles. Each cycle con- 
sisted of denaturation for 40 seconds at $94^{\circ} \mathrm{C}$, annealing for 40 seconds at $55^{\circ} \mathrm{C}$, and an extension for 120 seconds at $72^{\circ} \mathrm{C}$. A final extension step at $72^{\circ} \mathrm{C}$ for 5 minutes terminated the amplification. PCR product was analyzed by electrophoresis using a $1 \%$ agarose gel.

HU210, AM281, and kainic acid treatment in adult rats. Both HU210 and AM281 were dissolved in pure DMSO, and aliquots were stored at $-80^{\circ} \mathrm{C}$ with the final working concentration of $1 \mathrm{ml} / \mathrm{kg}$ body weight. Two doses of HU210 were used, 25 or $100 \mu \mathrm{g} / \mathrm{kg}$, which produce either nondetectable or severe behavioral changes, respectively, including ataxic walking and deep sleep. Only 1 dose of AM281, $3 \mathrm{mg} / \mathrm{kg}$, was employed, because this dose effectively antagonizes the behavioral effects produced by HU210 (8). Two injection protocols were utilized. To detect the acute effects of cannabinoid on cell proliferation in the hippocampus, rats received a single injection of vehicle, 25 or $100 \mu \mathrm{g} / \mathrm{kg}$ of HU210, or $3 \mathrm{mg} / \mathrm{kg}$ of AM281. To examine the chronic effects, rats received twice daily injections of vehicle, 25 or $100 \mu \mathrm{g} / \mathrm{kg}$ of HU210, or $3 \mathrm{mg} / \mathrm{kg}$ of AM281 for 10 days. Three rats received kainic acid injection $(10 \mathrm{mg} / \mathrm{kg}$, i.p.), and 1 hour after epileptic status, rats received sodium pentobarbital to stop behavioral seizures (31). One day after kainic acid injection, rats were killed for TUNEL and Fluoro-Jade B staining.

BrdU labeling in adult rats. Male Long-Evans, Wistar, and Fischer 344 rats weighing 220-250 g received i.p. injections of $50 \mathrm{mg} / \mathrm{kg}$ of BrdU (SigmaAldrich). Three BrdU injection paradigms were used. To identify the possible expression of $\mathrm{CB} 1$ receptors in dividing cells in the hippocampal dentate gyrus, rats received a single dose of BrdU 2 hours after HU210 and were perfused 2 hours later. To examine cell proliferation in the hippocampus, rats received 2 doses of BrdU ( 2 hours after the last HU210) with a 2-hour interval and were killed 24 hours after the last BrdU injection. To investigate differentiation of newborn cells in the hippocampus, rats received 4 doses of BrdU (12 hours after the last HU210) with 12-hour intervals and were allowed to survive for 1 month after the last BrdU injection.

Immunohistochemistry for adult rats. Under anesthesia with sodium pentobarbital $(50 \mathrm{mg} / \mathrm{kg}$, i.p.), rats were perfused transcardially with $0.9 \%$ saline, followed by $4 \%$ paraformaldehyde in $0.1 \mathrm{M} \mathrm{PBS}(\mathrm{pH} 7.4)$. The brains were removed, post-fixed for 2 hours in the same fixative, and placed in $20 \%$ sucrose until they sank. Coronal sections $(40-\mu \mathrm{m}$ thickness) through the entire hippocampus were cut on a sliding microtome and stored in PBS. Immunohistochemical detection of single BrdU labeling was conducted with previously described protocols (16). Briefly, freefloating sections were pretreated in $50 \%$ formamide $/ 2 \times \operatorname{SSC}$ buffer $(0.3 \mathrm{M}$ $\mathrm{NaCl}, 0.03 \mathrm{M}$ sodium citrate) at $65^{\circ} \mathrm{C}$ for 2 hours and were incubated in $2 \mathrm{M} \mathrm{HCl}$ at $37^{\circ} \mathrm{C}$ for 30 minutes. After a 10 -minute wash in $0.1 \mathrm{M}$ borate buffer ( $\mathrm{pH} 8.5$ ) to neutralize the $\mathrm{HCl}$, sections were incubated in mouse anti-BrdU antibody (1:1,000; Sigma-Aldrich) at $4^{\circ} \mathrm{C}$ for 36 hours. Sections were washed again and incubated in biotinylated goat antimouse secondary antibody (1:250; Vector Laboratories) for 2 hours at room temperature, followed by wash in PBS and an incubation in avidinbiotin-peroxidase complex for 2 hours. After a final wash, sections were reacted for peroxidase enzyme activity by using $3,3^{\prime}$-diaminobenzidine. Immunohistochemical detection of single NeuN labeling using mouse anti-NeuN antibody (1:2,000; Chemicon International) was conducted with protocols similar to those described above, except pretreatment with formamide and $\mathrm{HCl}$ was omitted. The specificity of immunolabeling was verified by controls in which the primary antibody was omitted.

For double immunofluorescence staining, DNA in the sections was first denatured to expose the antigen, as described above. Sections were then incubated at $4{ }^{\circ} \mathrm{C}$ for 36 hours in a cocktail solution containing sheep anti-BrdU antibody (1:500; Cedarlane Laboratories Ltd.) and mouse antiNeuN antibody (1:500; Chemicon International). After multiple washes in PBS, sections were incubated for 4 hours in Alexa Fluor 488-conjugated donkey anti-sheep secondary antibody preabsorbed with goat $\operatorname{IgG}(1: 400$;
Invitrogen Corp.) and Alexa Fluor 568-conjugated goat anti-mouse secondary antibody (1:400; Invitrogen Corp.). Sections were mounted on gelatinized slides and coverslipped.

TUNEL stain and Fluoro-Jade B stain. Three groups of 3 rats each receiving no treatment (control), chronic HU210 injection, and kainic acid injection were perfused with $4 \%$ paraformaldehyde as described above. Several series of coronal sections $(40-\mu \mathrm{m})$ through the hippocampus were cut on a sliding microtome. One series of sections was stained with Fluoro-Jade B stain according to the manufacturer's instruction (Histo-Chem Inc.) and our previous study (31). Adjacent sections were stained with a TUNEL staining kit according to the manufacturer's instruction (Trevigen Inc.).

Quantification of BrdU and NeuN labeling. Every sixth section through the dorsal hippocampus was processed for BrdU immunohistochemistry, resulting in each section being $240 \mu \mathrm{m}$ apart, thus ensuring the same cell would not be counted twice. All BrdU-positive cells in the entire granule cell layer (superior and inferior blades), SGZ (defined as a 2-cell-bodywide zone along the border of the granule cell layer), and the hilus were counted in each section by an experimenter who was not informed of the group assignment. The total number of BrdU-labeled cells per section was then averaged. This cell profile counting method is theoretically comparable to the true stereology cell counting, because we conducted random sampling (i.e., every sixth section was sampled), avoided double counting of the same cells (each section was $240 \mu \mathrm{m}$ apart), and counted all the cells labeled with BrdU regardless of their shape and size or of the volume of the dentate gyrus. Two recent studies have used similar cell counting methods $(59,60)$, which showed results indistinguishable from those provided by stereology cell counting (61).

For quantification of $\mathrm{BrdU} / \mathrm{NeuN}$ double-labeling cells, immunofluorescence images were obtained under a confocal laser-scanning microscope (LSM 510 META; Zeiss). Fifty BrdU-positive cells in each rat were randomly selected and then analyzed by orthogonal reconstructions from $z$-series ( $z$-step, $1 \mu \mathrm{m}$ ) to obtain the proportion of BrdU/NeuN double-labeling cells to BrdU-stained cells.

Stereological cell counting was performed for quantification of the total number of NeuN-stained neurons in the hippocampus of 2 groups of 3 rats each receiving no treatment (control) or chronic HU210 injection. We used an Olympus BX-51 microscope interfaced with a color digital camera (MicroFire; Optronics) and analyzed using the image analysis computer software Stereo Investigator (version 4.10; MicroBrightField Inc.). The analysis of the sections started from a random position at the origin of the hippocampus. Every sixth section was included such that the rostral 7 sections through the dorsal hippocampus in each animal were analyzed, and these 7 sections cover over $90 \%$ of the dorsal hippocampus. The contour delineations (left and right) of the dentate granule cell layer and CA3 pyramidal cell layer medial to an artificial line connecting the tips of the 2 granule cell blades were drawn using a $2.5 \times$ lens. Cells were counted using the optical fractionator method (62). Each counting frame was placed at an intersection of the lines forming a virtual grid that was randomly generated and randomly placed by the software within the granule or pyramidal cell layer. The software also controlled the motorized stage of the microscope that allowed scanning of the entire brain region by successively meandering from one counting frame to the other. Cells were counted using a 100x oil lens (NA 1.40) and were included in the measurements only when they came into focus within the dissector (dissector height, $11 \mu \mathrm{m}$; average thickness of mounted sections was $13 \mu \mathrm{m}$ ). The software calculated the estimated total number of cells in each brain structure. The precision of the individual estimations is expressed by the coefficient of error. This value expresses the intra-individual variation due to the stereological estimating procedure (i.e., sampling of sections and counting locations), thus providing the information necessary for determining 
whether more or less sampling should be performed. The inter-animal variation in total cell number is given by the coefficient of variation. Counting was performed blind to the treatment, and the sections were decoded only after completion of the analysis.

Behavioral testing. Rats received twice-daily injections of vehicle, AM281 $(3 \mathrm{mg} / \mathrm{kg})$, or HU210 (100 $\mu \mathrm{g} / \mathrm{kg})$ for 10 days, followed 12 hours later by $4 \mathrm{BrdU}$ injections at 12 hour intervals. Rats were subjected to behavioral testing 1 month later. NSF testing was conducted according to a previously described protocol (63). Food was removed from the home cage 48 hours before testing, but water was provided. Prior to testing, a single pellet of food weighing 3.5-4.5 g was placed on a platform in the center of the testing plastic box $(52 \times 48 \times 32 \mathrm{~cm})$ with the floor covered with a thin layer of wooden bedding. Rats were placed individually in a corner of the box and a stopwatch immediately started. The measure of interest was the latency to begin eating, defined as chewing of the food, not simply sniffing or playing with it. If animals had not eaten within 600 seconds, the test was terminated and the animals were assigned a latency score of $600 \mathrm{sec}-$ onds. Immediately after the test, rats were transferred to their home cages, and the latency to feed and the amount of food consumed in 15 minutes were measured, according to our pilot experiments. The whole process was videotaped and the latency to begin eating in the novel environment was measured by 2 experimenters blind to the treatment conditions.

For the FST, rats were placed individually in the testing plastic cylinder $(54 \mathrm{~cm}$ high $\times 35 \mathrm{~cm}$ in diameter) containing a 38 - $\mathrm{cm}$ water column $\left(22 \pm 1^{\circ} \mathrm{C}\right)$, according to previous studies $(41,42)$. Water was replaced between every trial. Two swimming sessions were conducted: an initial 15 -minute pretest, followed by a 5 -minute test 24 hours later. Following swim sessions, rats were removed from the cylinder, dried with a towel, and placed underneath a heating lamp for approximately 30 minutes before being returned to their home cages. Both pretest and test sessions were videotaped. Two observers blind to the treatment conditions scored the number of rats climbing in the first 5 minutes in the pretest session and for time spent immobile in the test session. Immobility was defined as floating passively in the water and only making slight movements to keep the head above the water.

Irradiation. Three groups of 5 rats each received twice-daily injections of vehicle (group 1), HU210 (group 2; $100 \mu \mathrm{g} / \mathrm{kg}$ ), or HU210 (group 3; $100 \mu \mathrm{g} / \mathrm{kg}$ ) for 10 days, followed 12 hours later by 4 BrdU injections at 12-hour intervals. All the rats were subjected to behavioral testing 1 month later. Group 3 rats also received irradiation using a Philips RT250 orthovoltage unit operated at $250 \mathrm{kV}$ and $15 \mathrm{~mA}$. Pre-irradiation dosimetry was performed using a PTW Unidos Electrometer type 10002 with Capintec Inc. Ionization Chamber model PR-06G. According to the method of Santarelli et al. (18), anesthetized rats were protected with lead shields that covered the entire body except the hippocampus. Dose rate measurements were performed with the ionization chamber (including its buildup cap) placed on the Perspex sheet. Readings were corrected for air temperature and pressure and indicated a dose rate of $67.2 \mathrm{cGy} / \mathrm{min}$ at a source-to-surface distance of $45 \mathrm{~cm}$. The total dose was $5 \mathrm{~Gy}$. Two $5 \mathrm{~Gy}$ doses were delivered 7 days apart, and the first dose was given 1 day after the first HU210 injection.

Statistics. All results are expressed as mean \pm SEM. Statistical analysis of the data was performed using standard 1-way ANOVA or 1-way ANOVA for repeated measures, followed by the Tukey post-hoc test. A 2-tailed Student's paired $t$ test was also used to compare the difference in values between 2 groups. Statistical significance was set at $P<0.05$.

\section{Acknowledgments}

This work was supported by grants from the Canadian Institutes of Health Research (CIHR) and the Heart and Stroke Foundation of Saskatchewan to X. Zhang, who is the recipient of the CIHR New Investigator Award. W. Jiang and S.-P. Ji were supported by Postdoctoral Fellowship Award from the Saskatchewan Health Research Foundation. We thank Y. Li and G. Kort for technical assistance.

Received for publication April 29, 2005, and accepted in revised form August 9, 2005.

Address correspondence to: Xia Zhang, Neuropsychiatry Research Unit, 103 Wiggins Road, University of Saskatchewan, Saskatoon, Saskatchewan, Canada S7N 5E4. Phone: (306) 966-2288; Fax: (306) 966-8830; E-mail: zhangxia@duke.usask.ca.

Yun Zhang and Lan Xiao contributed equally to this work.
1. Iversen, L. 2003. Cannabis and the brain. Brain. 126:1252-1270.

2. Pertwee, R.G. 2001. Cannabinoid receptors and pain. Prog. Neurobiol. 63:569-611.

3. Lemberger, L. 1980. Potential therapeutic usefulness of marijuana. Ann. Rev. Pharmacol. Toxicol. 20:151-172.

4. Robson, P. 2001. Therapeutic aspects of cannabis and cannabinoids. Br. J. Psychiatry. 178:107-115.

5. Baker, D., Pryce, G., Giovannoni, G., and Thompson, A.J. 2003. The therapeutic potential of cannabis. Lancet Neurol. 2:291-298.

6. Carlini, E.A. 2004. The good and the bad effects of (-) trans-delta-9-tetrahydrocannabinol (Delta 9-THC) on humans. Toxicon. 44:461-467.

7. Hall, W., Christie, M., and Currow, D. 2005. Cannabinoids and cancer: causation, remediation, and palliation. Lancet Oncol. 6:35-42.

8. Cui, S.S., et al. 2001. Prevention of cannabinoid withdrawal syndrome by lithium: involvement of oxytocinergic neuronal activation. J. Neurosci. 21:9867-9876.

9. Budney, A.J., Hughes, J.R., Moore, B.A., and Vandrey, R. 2004. Review of the validity and significance of cannabis withdrawal syndrome. Am. J. Psychiatry. 161:1967-1977.

10. Meyer, J.S., and Quenzer, L.F. 2004. Marijuana and the cannabinoids. In Psychopharmacology: drugs, the brain, and behavior. J.S. Meyer and L.F. Quenzer, editors. Sinauer Associates Inc. Sunderland, Massachusetts, USA. 327-345.

11. Fride, E., and Mechoulam, R. 2003. New advances in the identification and physiological roles of the components of the endogenous cannabinoid system. In Molecular biology of drug addiction. R. Maldonado, editor. Humana Press. Totowa, New Jersey, USA. 173-179.

12. Malberg, J.E. 2004. Implications of adult hippocampal neurogenesis in antidepressant action. J. Psychiatry Neurosci. 29:196-205.

13. Eisch, A.J., and Mandyam, C.D. 2004. Drug dependence and addiction, II: adult neurogenesis and drug abuse. Am. J. Psychiatry. 161:426.

14. Cameron, H.A., and McKay, R.D. 2001. Adult neurogenesis produces a large pool of new granule cells in the dentate gyrus. J. Comp. Neurol. 435:406-417.

15. van Praag, H., et al. 2002. Functional neurogenesis in the adult hippocampus. Nature. 415:1030-1034.

16. Jiang, W., Wang, J.C., Zhang, Z., Sheerin, A.H., and Zhang, X. 2004. Response of seizure-induced newborn neurons in the dentate gyrus of adult rats to second episode of seizures. Brain Res. 1006:248-252.

17. Shors, T.J. 2004. Memory traces of trace memories: neurogenesis, synaptogenesis and awareness. Trends Neurosci. 27:250-256.

18. Santarelli, L., et al. 2003. Requirement of hippocampal neurogenesis for the behavioral effects of antidepressants. Science. 301:805-809.

19. Dulawa, S.C., Holick, K.A., Gundersen, B., and Hen, R. 2004. Effects of chronic fluoxetine in animal models of anxiety and depression. Neuropsychopharmacology. 29:1321-1330.

20. Eisch, A.J., Barrot, M., Schad, C.A., Self, D.W., and Nestler, E.J. 2000. Opiates inhibit neurogenesis in the adult rat hippocampus. Proc. Natl. Acad. Sci. U. S. A. 97:7579-7584.

21. Nixon, K., and Crews, F.T. 2002. Binge ethanol exposure decreases neurogenesis in adult rat hippocampus. J. Neurochem. 83:1087-1093.

22. Abrous, D.N., et al. 2002. Nicotine self-administration impairs hippocampal plasticity. J. Neurosci. 22:3656-3662.

23. Yamaguchi, M., et al. 2004. Repetitive cocaine administration decreases neurogenesis in adult rat hippocampus. Ann. N. Y. Acad. Sci. 1025:351-362.

24. Jin, K., et al. 2004. Defective adult neurogenesis in CB1 cannabinoid receptor knockout mice. Mol. Pharmacol. 66:204-208.

25. Rueda, D., Navarro, B., Martinez-Serrano, A., Guzman, M., and Galve-Roperh, I. 2002. The endocannabinoid anandamide inhibits neuronal progenitor cell differentiation through attenuation of the Rap1/B-Raf/ERK pathway. J. Biol. Chem. 277:46645-46650.

26. Tsou, K., Brown, S., Sanudo-Pena, M.C., Mackie, K. and Walker, J.M. 1998. Immunohistochemical dis- 
tribution of cannabinoid CB1 receptors in the rat central nervous system. Neuroscience. 83:393-411.

27. Bonhaus, D.W., Chang, L.K., Kwan, J., and Martin, G.R. 1998. Dual activation and inhibition of adenylyl cyclase by cannabinoid receptor agonists: evidence for agonist-specific trafficking of intracellular responses. J. Pharmacol. Exp. Ther. 287:884-888

28. Howlett, A.C., et al. 2004. Cannabinoid physiology and pharmacology: 30 years of progress [review]. Neuropharmacology. 47(Suppl. 1):345-358.

29. Radeff-Huang, J., Seasholtz, T.M., Matteo, R.G., and Brown, J.H. 2004. G protein mediated signaling pathways in lysophospholipid induced cell proliferation and survival. J. Cell. Biochem. 92:949-966.

30. Kempermann, G., Gast, D., Kronenberg, G., Yamaguchi, M., and Gage, F.H. 2003. Early determination and long-term persistence of adult-generated new neurons in the hippocampus of mice. Development. 130:391-399.

31. Zhang, X., et al. 2002. Relations between brain pathology and temporal lobe epilepsy. J. Neurosci. 22:6052-6061.

32. Kempermann, G., Jessberger, S., Steiner, B., and Kronenberg, G. 2004. Milestones of neuronal development in the adult hippocampus. Trends Neurosci. 27:447-452.

33. Watts, G. 2004. High hopes for cannabinoid analgesia. BMJ. 329:257-258.

34. Martin, B.R., Mechoulam, R., and Razdan, R.K. 1999. Discovery and characterization of endogenous cannabinoids. Life Sci. 65:573-595.

35. Tzavara, E.T., Wade, M., and Nomikos, G.G. 2003. Biphasic effects of cannabinoids on acetylcholine release in the hippocampus: site and mechanism of action. J. Neurosci. 23:9374-9384.

36. Sulcova, E., Mechoulam, R., and Fride, E. 1998 Biphasic effects of anandamide. Pharmacol. Biochem. Behav. 59:347-352.

37. Welch, S.P., Dunlow, L.D., Patrick, G.S., and Razdan, R.K. 1995. Characterization of anandamide- and fluoroanandamide-induced antinociception and cross-tolerance to delta 9-THC after intrathecal administration to mice: blockade of delta 9-THC-induced antinociception. J. Pharmacol. Exp. Ther. 273:1235-1244

38. O'Sullivan, S.E., Kendall, D.A., and Randall, M.D. 2005. Vascular effects of Delta9-tetrahydrocannabinol (THC), anandamide and $\mathrm{N}$-arachidonoyldopamine (NADA) in the rat isolated aorta. Eur. J.
Pharmacol. 507:211-221.

39. Lutz, B. 2004. On-demand activation of the endocannabinoid system in the control of neuronal excitability and epileptiform seizures. Biochem. Pharmacol. 68:1691-1698.

40. Biscaia, M., et al. 2003. Chronic treatment with CP55,940 during the peri-adolescent period differentially affects the behavioural responses of male and female rats in adulthood. Psychopharmacology (Berl.). 170:301-308.

41. Lucki, I. 1997. The forced swimming test as a model for core and component behavioral effects of antidepressant drugs. Behav. Pharmacol. 8:523-532.

42. Cryan, J.F., Markou, A., and Lucki, I. 2002. Assessing antidepressant activity in rodents: recent developments and future needs. Trends Pharmacol. Sci. 23:238-245.

43. Gordon, J.A., and Hen, R. 2004. The serotonergic system and anxiety. Neuromolecular Med. 5:27-40.

44. Onaivi, E.S., Green, M.R., and Martin, B.R. 1990 Pharmacological characterization of cannabinoids in the elevated plus maze. J. Pharmacol. Exp. Ther 253:1002-1009.

45. Arevalo, C., de Miguel, R., and Hernandez-Tristan, R. 2001. Cannabinoid effects on anxiety-related behaviours and hypothalamic neurotransmitters. Pharmacol. Biochem. Behav. 70:123-131.

46. Marin, S., et al. 2003. Involvement of the kappaopioid receptor in the anxiogenic-like effect of CP 55,940 in male rats. Pharmacol. Biochem. Behav. 74:649-656.

47. Genn, R.F., Tucci, S., Marco, E.M., Viveros, M.P., and File, S.E. 2004. Unconditioned and conditioned anxiogenic effects of the cannabinoid receptor agonist CP 55,940 in the social interaction test. Pharmacol. Biochem. Behav. 77:567-573.

48. Hill, M.N., and Gorzalka, B.B. 2004. Enhancement of anxiety-like responsiveness to the cannabinoid $\mathrm{CB}(1)$ receptor agonist HU-210 following chronic stress. Eur. J. Pharmacol. 499:291-295.

49. Marco, E.M., et al. 2004. Involvement of 5-HT1A receptors in behavioural effects of the cannabinoid receptor agonist CP 55,940 in male rats. Behav. Pharmacol. 15:21-27.

50. Shearman, L.P., et al. 2003. Antidepressant-like and anorectic effects of the cannabinoid CB1 receptor inverse agonist AM251 in mice. Behav. Pharmacol. 14:573-582.

51. Tzavara, E.T., et al. 2003. The CB1 receptor antagonist SR141716A selectively increases monoami- nergic neurotransmission in the medial prefrontal cortex: implications for therapeutic actions. Br.J. Pharmacol. 138:544-553

52. Berrendero, F., and Maldonado, R. 2002. Involvement of the opioid system in the anxiolytic-like effects induced by delta (9)-tetrahydrocannabinol. Psychopharmacology (Berl.). 163:111-117.

53. Genn, R.E., Tucci, S., Marco, E., Viveros, M.P., and File, S.E. 2003. Anxiolytic and anxiogenic effects of the cannabinoid agonist CP 55,940 in animal tests of anxiety. J. Psychopharmacol. 17:A27.

54. Reynolds, B.A., and Weiss, S. 1996. Clonal and population analyses demonstrate that an EGFresponsive mammalian embryonic CNS precursor is a stem cell. Dev. Biol. 175:1-13.

55. Gritti, A., et al. 1996. Multipotential stem cells from the adult mouse brain proliferate and selfrenew in response to basic fibroblast growth factor. J. Neurosci. 16:1091-1100.

56. Persson, A.I., Thorlin, T., Bull, C., and Eriksson, P.S. 2003. Opioid-induced proliferation through the MAPK pathway in cultures of adult hippocampal progenitors. Mol. Cell. Neurosci. 23:360-372.

57. Harada, J., Foley, M., Moskowitz, M.A., and Waeber, C. 2004. Sphingosine-1-phosphate induces proliferation and morphological changes of neural progenitor cells. J. Neurochem. 88:1026-1039.

58. Kanemura, Y., et al. 2002. Evaluation of in vitro proliferative activity of human fetal neural stem/ progenitor cells using indirect measurements of viable cells based on cellular metabolic activity. J. Neurosci. Res. 69:869-879.

59. Malberg, J.E., Eisch, A.J., Nestler, E.J., and Duman, R.S. 2000. Chronic antidepressant treatment increases neurogenesis in adult rat hippocampus. J. Neurosci. 20:9104-9110.

60. Nixon, K., and Crews, F.T. 2004. Temporally specific burst in cell proliferation increases hippocampal neurogenesis in protracted abstinence from alcohol. J. Neurosci. 24:9714-9722.

61. Crews, F.T., Nixon, K., and Wilkie, M.E. 2004. Exercise reverses ethanol inhibition of neural stem cell proliferation. Alcohol. 33:63-71.

62. West, M.J. 1993. New stereological methods for counting neurons. Neurobiol. Aging. 14:275-285.

63. Bodnoff, S.R., Suranyi-Cadotte, B., Aitken, D.H., Quirion, R., and Meaney, M.J. 1988. The effects of chronic antidepressant treatment in an animal model of anxiety. Psychopharmacology (Berl.). 95:298-302. 